\title{
Renting versus Owning and the Role of I ncome Risk: The Case of Germany
}

\author{
Rainer Schulz* \\ Martin Wersing** \\ Axel Werwatz**
}

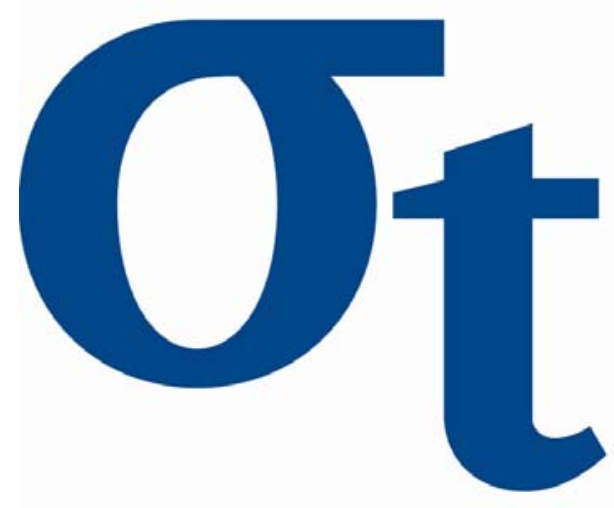

क)

$\nabla$

6

* University of Aberdeen, United Kingdom

** Technische Universität Berlin, Germany 


\title{
Renting versus Owning and the Role of Income Risk: The Case of Germany*
}

\author{
Rainer Schulz, Martin Wersing, and Axel Werwatz
}

November 2009

\begin{abstract}
*Wersing, corresponding author: SFB 649 Economic Risk, Technische Universität Berlin, Institut für Volkswirtschaftslehre und Wirtschaftsrecht, Straße des 17. Juni 135, 10623 Berlin, Germany, Tel: +49 (0)30 314 24742, Fax: +49 (0)30 3142 3691, martin.wersing@tu-berlin.de. Schulz: University of Aberdeen Business School, Edward Wright Building, Dunbar Street, Aberdeen AB24 3QY, United Kingdom, r.schulz@abdn.ac.uk. Werwatz: Technische Universität Berlin, Institut für Volkswirtschaftslehre und Wirtschaftsrecht, Straße des 17. Juni 135, 10623 Berlin, Germany and SFB 649, axel.werwatz@tu-berlin.de. We have benefited from comments on earlier versions of this paper by Bernd Fitzenberger, James Follain, Christian Hilber, Verity Watson and session and seminar participants at the AREUEA Annual Conference 2009, ERES 2008, Regensburg Conference on Real Estate Economics and Finance 2007, University of Aberdeen, Heriot Watt University, HumboldtUniversität zu Berlin, Universität Tübingen, Universität Hannover, and DIW Berlin. The usual disclaimer applies. Financial support from the Deutsche Forschungsgemeinschaft, SFB 649 Economic Risk, is gratefully acknowledged.
\end{abstract}




\begin{abstract}
In a world with complete markets and no transactions cost, the decision whether to rent or buy a home is separate from a household's professional income risk. If markets are incomplete and have frictions, however, professionspecific income risk, regional house price risk, and mobility needs will interact and should affect the tenure mode choice. Using panel data from West Germany, we establish homogeneous profession groups and estimate their regional net income risk and regional mobility. We then examine the impact of the risk and mobility variables on the tenure mode decision at the aggregate and the individual household level. We find that the diversification potential of renting affects the tenure mode choice as do mobility needs.
\end{abstract}

Keywords: Tenure mode choice, background risk, household mobility

JEL Classification: R21, G11, J24, C25 


\section{Introduction}

Choosing whether to rent or buy a home is a multifaceted and difficult task. Households have to grapple not only with the uncertainties of future housing cost, but also need to consider how the tenure mode choice matches conditions set by past decisions. The most important of these conditions is human capital. Early career decisions, such as the choice of an occupation and an industry, have a sizable and often irreversible impact on the specificity of human capital (Cunha and Heckman, 2007; Neal, 1995). If other measures to insure against the risk of profession-specific human capital are imperfect, then the exposure to this risk may affect the decision of whether to rent or buy.

Early empirical studies on households' tenure choice focussed on differences in the relative price and risk of renting and owning. In most developed countries, the imputed rent from owner-occupation is not taxed and user cost of owning decreases with the household's marginal tax rate, which is particulary valuable to households with high taxable income and should make them more likely to own. A household's tenure choice will be further affected by the risk difference of future house and rental prices. Finally, because a house purchase exposes the owner's portfolio to a single source of risk, sufficient wealth is required to hold a well-diversified portfolio. ${ }^{1}$

More recently, Ortalo-Magné and Rady (2002) argued that the tenure choice depends not on the risk of house and rental prices per se, but on the correlation of these prices with household's income and mobility requirements. First, renting a home instead of owning it exposes the household to future changes of the rental price. Owing a home effectively locks housing cost at a fixed level and eliminates uncertainty over the future rental price. This lock-in effect is more valuable the

\footnotetext{
${ }^{1}$ Rosen (1979) and Rosen and Rosen (1980) provide evidence for the impact of user cost on the tenure choice for the US and King (1980) for the UK. Rosen et al. (1984) considers additionally house and rental price risk and finds that households' tenure choice responds to the risk differential between both. Berkovec and Fullerton (1992) calibrate a general equilibrium model in which homeownership is encouraged by household's wealth and the potential of holding a well-diversified portfolio of assets.
} 
longer a household expects to stay in a region. Sinai and Souleles (2005) provide empirical evidence on this effect. Second, rental price uncertainty is not necessarily detrimental if it is positively correlated with the household's income. In this case, renting allows the household to diversify some of the net income risk. Consider a region that is dominated by one industry: If the industry is hit by a negative shock, the incomes of the those working in the industry will also experience a negative shock. This will lead to a decrease in demand for housing services and regional rental prices. Renters benefit from this decrease, while homeowners not only receive lower income, but also suffer from a decline of their housing wealth. Davidoff (2006) provides empirical evidence on this diversification effect. ${ }^{2}$ Third, if a household has to be mobile, then renting shields the household from house price resale risk and lowers transactions cost associated with the move. Even if the household expects to move to a region where house prices are hit by the same shock, making resale risk less of a concern, transactions cost will be substantial. Lower transactions cost of moving is a clear advantage for households in professions where the required job mobility is high. The studies of Haurin and Gill (2002), Henderson and Ioannides (1989) and Kan (2000) provide evidence on this effect, but do not consider the interaction with resale price risk.

In this study, we use the German Socio-Economic Panel (GSOEP) to establish homogeneous profession groups, their mobility needs, and constant-quality professionincome and regional rental price indices. We then examine if the diversification potential of renting plays a role for the tenure choice of different profession groups. Further, we examine if profession-specific mobility needs make renting more likely. In addition to the analysis at the level of profession-region groups, we also analyse the tenure choice at the household level. Each household belongs to a professions

\footnotetext{
${ }^{2}$ Diaz-Serrano (2005) studies the influence of idiosyncratic - not profession-systematic - income risk. He finds that greater income uncertainty increases a household's propensity to rent. He interprets this result as evidence for restrictions in accessing the mortgage market faced by households exposed to greater idiosyncratic income risk.
} 
group and is exposed to group's systematic income risk, but other observed and unobserved household characteristics may also impact on the tenure choice.

Our approach is similar to Davidoff (2006, Section 4.2.), but extends it by using household panel data. This allows us to construct homogeneous profession groups by clustering over industries and occupations; these groups are stable over time in the sense that intra-group moves are likely, but inter-group moves are unlikely. Using the household information in the panel, we can compute constant-quality income indices for the different profession groups and use these to measure the systematic net income risk. ${ }^{3}$ Further, we model mobility requirements explicitly and find this variable to be very important. Exploiting the panel structure, we can also fit dynamic models of households' tenure choices, making our analysis robust with respect to different econometric specifications.

We find at the aggregate profession-region group level that the diversification potential of renting has a significant influence on rental shares. A decrease of the diversification potential variable, which relates the net income risk if owning to the risk if renting, by $10 \%$ (thereby increasing diversification potential of renting) increases the share of renters by about $1 \%$. Furthermore, the renters' share increases the shorter the expected remaining residence duration is, i.e., the more mobile households in a profession group have to be. A decrease of the expected duration by one year increases the probability to rent by about $3 \%$. The results at the individual household level are very similar and hold even after controlling for the substantial state dependence of households' tenure choices and after controlling for unobserved heterogeneity.

Our study on the German housing market therefore supports evidence found for the US market. Renting is not just for those who cannot afford to buy a home, but can provide valuable benefits in the context of a household's risk management. Seen

\footnotetext{
${ }^{3}$ Davidoff's household data is a cross-section from the 1990 US Census. He measures income risk using region-industry average incomes and matches with respect to household head's industry according to the official SIC classification.
} 
in this light, there are no reasons why governments should favor one tenure mode over the other. ${ }^{4}$

The remainder of this paper is organized as follows. Section 2 provides theoretical motivation. Section 3 presents the data and explains the construction of the key variables. The empirical implementation is explained in Section 4. Section 5 presents the empirical results. Section 6 concludes. A Supplement, which provides further details, is available from the authors upon request.

\section{Theoretical motivation}

Most human capital is acquired early in life and becomes quite specific during the course of one's professional career. The future income from this specialized capital is risky and cannot be fully hedged. If we take it as given that the tenure choice is made after the human capital has been formed, then the comovement between income and regional rental prices may allow members of some professions to diversify part of their systematic income risk through their tenure choice. Moreover, if the acquired human capital is in a profession that requires mobility, then this may also impact on this choice.

We expose the tenure choice problem with a discrete time utility maximization framework. ${ }^{5}$ Dwellings are homogeneous and are supplied by absent risk neutral

\footnotetext{
${ }^{4}$ Owner-occupied housing is favored relative to other investments because income (imputed rent) is not taxed. Rental housing investments receive favorable treatment too (accelerated depreciation allowances, financing and modernization subsidies), which should impact on the rental price via increased supply. The net effect is far from obvious. White and White (1977) calculate for the US that owner-occupation is favored and that richer owner households benefit. Hubert (1998) suggests that the private rental sector may have received slightly more favorable treatment in (West) Germany.

${ }^{5}$ Ortalo-Magné and Rady (2002) and Davidoff (2006) provide similar expositions.
} 
agents, who are prepared to act as landlords or to sell the dwellings. Rents follow

$$
R_{r, t}=R+\varepsilon_{r, t}+\sum_{k=1}^{t-1} \phi^{k} \varepsilon_{r, t-k} \quad t \geqslant 1,
$$

where $r$ indicates the region, $|\phi|<1$, and $\varepsilon_{r, t}$ is white noise, possibly contemporaneously correlated between the regions. The household makes the decision in period 0 and $R_{r, 0}=R$ in all regions. The required return rate for a housing investment is $i$ and the house price is $P=R / i$ in period 0. A household's professional career lasts $T$ periods; a profession-related move might be necessary in $1<t^{\prime} \leqslant T$.

Expected utility is additive time-separable and period utility depends on housing and a composite consumption good. The direct utility contribution of homogeneous housing is identical for renters and owners. ${ }^{6}$ The indirect contribution of housing is via the net income that can be spent on the consumption good. We assume that the household likes high expected net income, but dislikes risk, measured with the variance of the net income. Based on period 0 information, the household decides for the tenure mode that provides more expected utility.

The net income is the gross income $Y_{t}$ minus cost for housing (rent or mortgage payments). Assuming that a house purchase requires no down-payment and that the household stays until $T$ in the dwelling, a renter's net income is $Y_{t}-R_{r, t}$ for $t \in\{1, \ldots, T\}$; an owner's net income is

$$
\begin{aligned}
Y_{t}-i P & \text { for } 1 \leqslant t<T \\
Y_{T}-(1+i) P+P_{r, T} & \text { for } t=T .
\end{aligned}
$$

The owner thus locks housing cost in at $i P$ for all but the last period.

Conditional on period 0 information, the expected net income is $\mathrm{E}\left[Y_{t}\right]-R$ in all periods and the same for renters and owners. The conditional variances, however, are different: for a renter, they are

$$
\operatorname{Var}\left[Y_{t}\right]+\operatorname{Var}\left[R_{r, t}\right]-2 \operatorname{Cov}\left[Y_{t}, R_{r, t}\right]
$$

\footnotetext{
${ }^{6}$ By assuming homogeneous dwellings, we ignore intra-region moves, such as trading up.
} 
and for an owner

$$
\begin{aligned}
\operatorname{Var}\left[Y_{t}\right] & \text { for } 1 \leqslant t<T \\
\operatorname{Var}\left[Y_{T}\right]+\operatorname{Var}\left[P_{r, T}\right]+2 \operatorname{Cov}\left[Y_{T}, P_{r, T}\right] & \text { for } t=T .
\end{aligned}
$$

If income and rents are positively correlated, renting diversifies gross income risk, but it depends on the magnitude of the correlation if renting provides a smoother net income in periods $t<T$ than owning. The owner household is insulated from changing rents in all but the last period. Using (1), owner's net income variance for the last period $T$ becomes

$$
\operatorname{Var}\left[Y_{T}\right]+\delta^{2} \operatorname{Var}\left[R_{r, T}\right]+2 \delta \operatorname{Cov}\left[Y_{T}, R_{r, T}\right]
$$

with $\delta=\phi(1+i-\phi)^{-1}$. If the rental process has no memory, $\phi=0$, then $\delta=0$ and ownership insulates from varying housing cost even in the last period. The reasoning is simple: The house price in $T$ is the present value of the expected future rents; if these rents are not correlated with past rents, then the future price is not uncertain. If rents have a memory, $\phi \neq 0$, then owners are exposed to part of the accumulated rent risk in the last period. Ceteris paribus, it is therefore more likely that a household will rent if the correlation between income and rents is high.

The model can be extended in three directions. First, we can allow households to move to another region in $1 \leqslant t^{\prime}<T$. Obviously, households do not have to commit in period 0 to the tenure mode they will choose in $t^{\prime}$. This implies that their tenure choice today is unaffected by the choice they will make after they move to the new region. Renter's consumption risk in $t^{\prime}<t \leqslant T$ is not influenced by their current tenure mode. The same holds if they buy in the new region: This result is driven by the assumption that no down-payment is required. Second, if a down-payment is required, then the previous tenure mode has an impact on the riskiness of the future tenure mode. This is most obvious for an owner who sells the house in $t^{\prime}$ and buys one in the other region. If rents and therefore prices in the two regions are correlated, so will the resale price and the new down-payment. 
The sign and magnitude of inter-regional rent correlation determines if owner's net income becomes more or less risky. ${ }^{7}$ Third, we can include moving cost. Selling a house comes with large transactions cost, which a household that has to be mobile presumably wants to avoid.

The above exposition motivates three hypotheses: First, the specificity of human capital should allow us to establish homogeneous profession groups, whose members are exposed to the same systematic income risk. Second, if renting diversifies part of the profession-specific income risk and smoothes net income, i.e., $\operatorname{Var}\left[Y_{t}-R_{t}\right]<$ $\operatorname{Var}\left[Y_{t}\right]$, then a household should be more likely to rent. Third, ceteris paribus, a household is more likely to rent the shorter the expected period of stay in the dwelling. Although owning isolates the household from rental price risk for the time of the stay, it also brings higher moving cost (because of the transactions cost of the house sale). This may more then outweigh the lock-in effect.

The next section presents the data and explains how we construct necessary key variables. Based on Hypothesis 1, we establish homogenous profession groups. We then test if diversification potential (Hypothesis 2) and mobility requirements (Hypothesis 3) impact on the tenure choice. To do so, we fit rental share regressions at the profession-region level and binary response models at the household level. These models include the key variables and control for other well-established determinants of tenure choice such as potential credit constraints, differential tax treatment, and household composition.

\section{Data}

This section presents the data and explains how we establish homogeneous profession groups, compute profession-specific income indices, regional rent indices, and measure the mobility needs of profession groups.

\footnotetext{
${ }^{7}$ Under the special circumstances that the rental process has no memory, the owner household is again perfectly insulated from all housing cost risk.
} 
Our main data are from the GSOEP for the years 1984 to $2004 .^{8}$ The yearly panel is a representative survey of economic conditions for German households and their adult members. Further, we use information on regional house prices provided by the Ring Deutscher Makler (RDM). All price and income variables are deflated with the German CPI excluding housing services (from the Federal Statistical Office). ${ }^{9}$

We restrict the analysis to households living in one of the 30 West German NUTS2 regions. ${ }^{10}$ We exclude households living in the East because the housing market there is still adapting to a market-based system. We further focus on households whose head is between 18 and 65 years of age. Households who live in nursing and retirement homes are excluded.

The main sample covers the years 1984 to 2004 and has 36625 observations on 3476 individual household. This panel is unbalanced, because some households leave and enter during the observation period. On average, $53 \%$ of the households are tenants; the majority rents in the private sector, where rental prices are freely negotiable between landlords and tenants. ${ }^{11}$ The duration of a rental contract is in principle indefinite and landlords cannot give notice without further justification. Households are thus well-protected from eviction risk. Landlords, on the other

\footnotetext{
${ }^{8}$ The data were made available to us by the German Socio-Economic Panel Study at the German Institute for Economic Research (DIW), Berlin.

${ }^{9}$ The RDM is an association of real estate professionals that publishes annual surveys on house price levels in German cities. This information is not based on systematic statistics but inquiries among members. Nevertheless it should provide a reasonable good picture of regional price levels. To obtain regional house price levels, we aggregate the data on cities in a region by weighting with city populations. Population figures are taken from the Gemeindeverzeichnis of the Federal Statistical Office.

${ }^{10}$ The Nomenclature of Territorial Units for Statistics level 2 (NUTS2) defined by Eurostat correspond to Government regions. A government region (Regierungsbezirk) is an administrative subdivision of a certain federal state (Bundesland).

${ }^{11}$ According to Kirchner (2007), in 1993, 47.5\% of all dwellings in West Germany were in the private rental sector, $10.9 \%$ in the social rental sector and $41.6 \%$ are owner-occupied. Given that we exclude some households, this is in line with our main sample.
} 
hand, have the right to adjust rental prices of existing contracts to market levels. ${ }^{12}$ The second column in Table 1 provides summary statistics on the socio-economic characteristics of the households in the main sample; the third and second last variables will be explained below.

[Table 1 about here.]

\subsection{Profession grouping}

The GSOEP reports both the industry (NACE Rev.1) and occupation (ISCO-88) of all employed household members. The administratively defined industry and occupation categories, however, do not necessarily reflect individual careers. As people are likely to change jobs during their life, possibly moving to new industries or occupations, measures of income risk based on these categories are likely to differ from the systematic income risk individuals are truly exposed to.

Following Shiller and Schneider (1998), we use a cluster analysis to find professions whose members define stable groups. To build these groups our cluster algorithm uses the transition matrix between 126 initially observed industry-occupation categories defined by 14 main NACE industries and 9 major ISCO-88 occupations. We estimate the transition probabilities from all household heads and spouses who have been in the GSOEP for at least two years during the period 1984 to 2004 . The cluster algorithm groups the initial categories in such a way that individuals are unlikely to move between clusters. Further details on the cluster analysis are given in the Appendix.

[Table 2 about here.]

Table 2 presents the allocation of industries and occupations to professions, along with broad categories we have assigned to the groups. We find 14 professions that are

\footnotetext{
${ }^{12} \mathrm{~A}$ thorough discussion of the institutional and legal setting in Germany can be found in Tomann (1990) and Hubert (1998).
} 
characterized by high transition probabilities within and low transition probabilities between groups (see Table 7 in the Appendix). The allocation of industries and occupations to the 14 professions largely follows intuition. For instance, professions in the health or financial sector comprise almost all occupations (Group 8 and Group 14). Craftsman and the like, on the other hand, form their own professional group regardless of the industry (Group 9).

\subsection{Key variables}

To measure the diversification potential of renting, we compute annual income and rent series for the 420 profession-region groups and the 30 regions as follows: First, we run separate fixed effects panel regressions for the 14 professions and the 30 regions using the GSOEP data on income and apartment rents for the period 1984 to 2004. The estimated coefficients of the included time dummies give us constantquality index series. Second, we convert the index series into level series by using the median profession income level in each region for the year 1995 and, respectively, by using the median rent for each region in the same year. ${ }^{13}$ This gives us the rent series. Third, the final income level series are computed as weighted averages of the income received if employed and the benefit received if unemployed. Unemployment replacement rates are provided by the OECD. ${ }^{14}$ The weights are based on the actual unemployment rates of panel members within a given profession and year. The Supplement provides further details.

We then compute the diversification measure for each profession and region as the ratio of professions' net income growth rate risk if renting to the risk if owning.

\footnotetext{
${ }^{13}$ The income movement of certain professions may also depend on region-specific factors. Thus, one would ideally like to compute constant-quality income indices for each of the 420 professionregion groups. Due to the lack of sufficient observations on the profession-region level in the GSOEP, we are however not able to estimate precise enough income indices for each profession-region group.

${ }^{14}$ The OECD summary measure of replacement rates is defined as the average of the gross unemployment benefit replacement rates for two earnings levels, three family situations and three durations of unemployment. For further details, see Martin (1996).
} 
Specifically, the real growth rate of net income if renting and the real growth rate of income net of (fixed) user cost are calculated as

$$
\Delta Y_{p r, t}^{(R e n t)}=\frac{\left(Y_{p r, t}-R_{r, t}\right)-\left(Y_{p r, t-1}-R_{r, t-1}\right)}{\left(Y_{p r, t-1}-R_{r, t-1}\right)}
$$

and

$$
\Delta Y_{p r, t}^{(\overline{R e n t})}=\frac{\left(Y_{p r, t}-\bar{R}_{r}\right)-\left(Y_{p r, t-1}-\bar{R}_{r}\right)}{\left(Y_{p r, t-1}-\bar{R}_{r}\right)} .
$$

$Y_{p r, t}$ is the real income level for profession $p$ in region $r$ and year $t$. The real rent level in region $r$ and year $t$ is $R_{r, t} . \bar{R}_{r}=21^{-1} \sum_{t=1984}^{2004} R_{r, t}$ is the corresponding withinregion time average of rents. $\Delta Y_{p r, t}^{(\text {Rent })}$ measures the growth of real net income if the household rents at the prevailing rental price. Correspondingly, $\Delta Y_{p r, t}^{(\overline{R e n t})}$ measures the real net income growth of a household that has 'looked-in the rent' at the level $\bar{R}_{r}$ by owner-occupation. (3) and (2) imply that, on average, owning and renting have the same price, but their riskiness differs.

Two comments are in order: First, we focus on professional income and ignore that households may have other sources of income, such as income from savings and share investments. The GSOEP reports if a household owns other assets, but does not specify the market value or the income from such assets. We thus cannot include such income in $Y_{p r, t}$. In the empirical analysis below, we control for households who have no assets. Because a portfolio of assets facilitates income risk diversification, it may act as substitute for renting, making renting more likely for households which cannot use this substitute. ${ }^{15}$ Second, because important information on mortgage financing and tax treatment is not reported in the GSOEP, we cannot compute the user cost at the household level and hence at the profession group level. The regional user cost $\bar{R}_{r}$ is then for the average household; in the empirical applications we control for the tax treatment (by using labor income as regressor) and for changes in interest and tax rates by using time dummies.

\footnotetext{
${ }^{15}$ No wealth can also prevent a household from obtaining a mortgage loan, because the household cannot provide the downpayment. Banks will require a downpayment to share risk and it should be the larger the larger the correlation between income and prices (and hence rents).
} 
Given the profession group income growth series, the diversification potential measure for each of the 420 profession-region groups is computed as

$$
\begin{aligned}
\rho_{p r} & =\frac{\operatorname{Var}\left(\Delta Y_{p r, t}^{(\overline{R e n t})}\right)}{\operatorname{Var}\left(\Delta Y_{p r, t}^{(\text {Rent })}\right)} \\
& =\frac{\sum_{t=1985}^{2004}\left(\Delta Y_{p r, t}^{(\overline{R e n t})}-\Delta \bar{Y}_{p r}^{(\overline{R e n t})}\right)^{2}}{\sum_{t=1985}^{2004}\left(\Delta Y_{p r, t}^{(\text {Rent })}-\Delta \bar{Y}_{p r}^{(\text {Rent })}\right)^{2}} .
\end{aligned}
$$

If $\rho_{p r}=1$, the net income risk if renting is exactly the same as the riskiness of net income risk with locked-in user cost. There is thus no extra diversification potential of renting. If $\rho_{p r}>1$, the co-movement between income and rent growth will allow household in profession $p$ to exploit diversification benefits. If $\rho_{p r}<1$, negative correlation between profession-specific income and regional rent growth does not allow to diversify income risk by renting.

Note that (4) only varies across profession-region groups. In some households another member earns professional income and this intra-household risk sharing might impact on the tenure choice. In some of our empirical specifications, we will consider such intra-household risk sharing by using the following variant of the diversification potential measure: We replace the real income levels $Y_{p r, t}$ in equations (3) and (2) for double-earner households with

$$
Y_{h, t}=\frac{1}{2}\left(Y_{p(H) r, t}+Y_{p(S) r, t}\right)
$$

where the subscripts $p(H)$ and $p(S)$ denote the profession of the household head and the spouse, respectively. In this case, the resulting series of household's net income growth rate, $\Delta Y_{h, t}^{(\cdot)}$, depends both on household head's and spouse's profession. The household specific measure of the diversification potential of renting is calculated along the lines of equation (4).

To measure household's mobility, we estimate a parametric survival model of residence duration, using information on mobility histories of households in the GSOEP. 
From the fitted model we then predict the expected remaining residence duration of each household, which is the expected length of stay after the household has spent time $\tau$ in its current residence. The expected remaining residence duration is further allowed to depend on the profession of the household head and the composition of the household.

To be specific, let $T \geq 0$ be a continuous random variable which represents the duration of household tenure, that is the elapsed time since a household has last moved. $T$ is characterized by a (parametric) distribution function $F(\tau)=P(T \leq \tau)$. The expected remaining duration is formally defined by $\mu(\tau)=\mathrm{E}[T-\tau \mid T>\tau]$, i.e.,

$$
\mu(\tau)=\frac{1}{S(\tau)} \int_{\tau}^{\infty}(u-\tau) f(u) d u .
$$

Here, $S(\tau)=1-F(\tau)$ denotes the survival function and $f(\tau)$ is the density. It is obvious that the expected remaining duration at $\tau=0$ is the expected value of $T$. Closed-form solutions for the integral on the right hand side of equation (5) exist for a number of well-known life time distributions, see for example Lai and Xie (2006).

We specifically assume that residence spells have a lognormal distribution given possibly time-varying household characteristics $\mathbf{x}(\tau) .{ }^{16}$ This implies that $\ln (\tau)$ has a conditional normal distribution $N\left(\mathbf{x}(\tau) \boldsymbol{\beta}, \sigma^{2}\right)$. Under the lognormal assumption the mean residual time function is given by

$$
\mu(\tau)= \begin{cases}\exp \left\{\mathbf{x}(\tau) \boldsymbol{\beta}+0.5 \sigma^{2}\right\} & \text { if } \tau=0 \\ \frac{1-\Phi\left(\frac{\ln (\tau)-\mathbf{x}(\tau) \boldsymbol{\beta}-\sigma^{2}}{\sigma}\right)}{1-\Phi\left(\frac{\ln (t \tau)-\mathbf{x}(\tau) \boldsymbol{\beta}}{\sigma}\right)} \exp \left\{\mathbf{x}(\tau) \boldsymbol{\beta}+0.5 \sigma^{2}\right\}-\tau & \text { if } \tau>0\end{cases}
$$

where $\Phi(\cdot)$ denotes the standard normal distribution function. Note that $\mu(\tau)$ initially decreases and then monotonically increases with the elapsed time of stay. Given estimates of the unknown parameters $\boldsymbol{\beta}$ and $\sigma$, we can easily impute the expected remaining residence duration for each household by plugging the elapsed time $\tau$ and household characteristics at that time in equation (6).

\footnotetext{
${ }^{16}$ We have discriminated between a number of parametric distributions, including the exponential, lognormal, log-logistic, and Weibull distribution. The lognormal fitted the data best.
} 
In order to obtain estimates of $\boldsymbol{\beta}$ and $\sigma$, we run tobit-type regressions using a flow sample of households' residence durations extracted from the GSOEP. In particular, we regress the log of households' observed residence duration on a vector of dummy variables representing household head's profession and other household characteristics. Among these are the age of the household head at the beginning of the duration, household size, marital status, and gender. Detailed results of the survival analysis are given in the Appendix.

Table 3 presents summary statistics of income and rental price growth for the profession groups and the different regions over the whole sample and for the year 1995. Between 1984 and 2004 the average (across and within regions) standard deviation of real rent growth was about 3.9 percent per year. For the same time period the average (across and within professions) standard deviation of real income growth rates was about 3.4 percent. The Table also gives summary statistics for the year 1995. In this year, 56 percent of West German households rented their home. On average they spent approximately 15 percent of their gross professional income for rental payments. There is, however, substantial variation in rental shares, rent levels, and income levels across the regions.

[Table 3 about here.]

The median of the diversification potential measure is 0.98 . As evidenced by the means of the measure for the bottom and top halves of its distribution, the income smoothing potential from renting varies substantially across professions and regions. Members of profession-region groups with a measure below its median value have on average a 9.53 percent higher net income variance if renting. Households living in profession-region groups with a measure above its median value, on the other hand, reduces their net income variance on average by about 4.49 percent if renting their home.

Households' residential mobility is rather small. The average (across professions) expected remaining residence duration was about 13.3 years in 1995 . On the level of 
profession-region groups, the average standard deviation of this variable is only 1.86 years. It must be noted, however, that the expected remaining residence duration not only depends on a household's profession, but also its composition. Thus averaging across households of the same profession considerably reduces the variation of this variable. Summary statistics of the two variables are also given at the bottom of Table 1 for the three sub-samples.

\section{Empirical implementation}

This section explains how we use the two key variables to test if renting is more likely the higher the diversification potential of renting (Hypothesis 2) and the shorter the expected remaining residence duration (Hypothesis 3). We use several different empirical specifications to examine the tenure choice of households both at the aggregate profession group level and at the household level. The specifications are explained in this section; Section 5 presents the empirical results.

\subsection{Analysis at the profession group level}

Let $\bar{y}_{p r, t}$ denote the observed proportion of renter households within professionregion group ( $p r)$ and year $t$. Here, $p$ indexes the profession of the household head and $r$ the region the household lives in. We specify the corresponding population quantity with the probit model

$$
\bar{y}_{p r, t}=\Phi\left(\beta_{0}+\beta_{1} \rho_{p r}+\beta_{2} \bar{\mu}(\tau)_{p r, t}+\overline{\mathbf{x}}_{p r, t} \boldsymbol{\delta}\right)+\varepsilon_{p r, t}
$$

where $\Phi(\cdot)$ denotes the standard normal distribution function, and the idiosyncratic error $\varepsilon_{p r, t}$ has mean zero. The profession-region specific diversification potential if renting is captured by our time-constant measure $\rho_{p r}$. The expected remaining residence duration, $\bar{\mu}(\tau)_{p r, t}$, is the mean of this variable for all households belonging to the group in year $t . \overline{\mathbf{x}}_{p r, t}$ is a vector collecting group means of socio-economic 
controls. We further include a full set of profession dummies and time dummies in $\overline{\mathbf{x}}_{p r, t}$.

To estimate the coefficients in equation (7), we use the linear approximation to the inverse of the standard normal distribution function around the observed rental share

$$
\Phi^{-1}\left(\bar{y}_{p r, t}\right)=\beta_{0}+\beta_{1} \rho_{p r}+\beta_{2} \bar{\mu}(\tau)_{p r, t}+\overline{\mathbf{x}}_{p r, t} \boldsymbol{\delta}+u_{p r, t}
$$

where the error term $u_{p r, t}$ has zero mean and has heteroscedastic variance of known form. ${ }^{17}$ Thus, estimates of the coefficients can be obtained by standard (weighted) least squares methods. In order to assess the magnitude of the effect of the explanatory variable on rental shares, we compute partial effects of the variables under scrutiny. For instance, the estimated partial effect of $\rho_{p r}$ on rental shares is given by $\phi\left(\widehat{\beta}_{0}+\widehat{\beta}_{1} \rho+\widehat{\beta}_{2} \bar{\mu}(\tau)+\overline{\mathbf{x}} \widehat{\boldsymbol{\delta}}\right) \widehat{\beta}_{1}$, where the explanatory variables are set to fixed values of interest. We expected the partial effect of the diversification potential variable to be positive (and thus $\beta_{1}>0$ ) and the effect for the expected remaining duration to be negative (and thus $\beta_{2}<0$ ).

There are three econometric aspects associated with regression equation (8), which need to be addressed. First, the heteroscedastic error term suggests that weighted least squares regressions produce efficient parameter estimates. Households within the same profession-region group, however, may share unobserved characteristics, which in turn can lead to substantial reduction of heteroscedasticity (Dickens, 1990). Furthermore, pooling cross sections of profession-region groups over time is likely to introduce serial correlated error terms. To avoid these potential misspecifications of the weighted least squares estimator, we run ordinary least squares regressions. OLS delivers consistent, yet inefficient, parameter estimates.

Second, the regression given by equation (8) involves generated regressors, namely the relative riskiness of renting $\rho_{p r}$ and the mean residual time $\bar{\mu}(\tau)_{p r, t}$. We thus need to adjust standard errors accordingly. As we are primarily interested in the

\footnotetext{
${ }^{17}$ A detailed discussion of this approximation can be found in Amemiya (1981).
} 
partial effects of the explanatory variables on rental shares, we use bootstrap standard errors (Efron and Tibshirani, 1993). We consider 200 replications from the set of profession-region groups, and based on the resulting bootstrap sample estimate partial effects. The standard deviations across the replications serve as the bootstrap standard errors.

Third, the share of renters of different professions in different regions largely reflects the cumulative attainment of either tenure mode among group members. Given the substantial transactions cost associated with adjustments to housing tenure, a static analysis likely attributes historical choices to today's conditions. To allow for the dynamic nature of households' tenure choices, we have to model the rent or buy decision on the individual household level. This allows to control explicitly for (unobserved) heterogeneity across households within the same profession-region group.

\subsection{Analysis at the household level}

Households within profession-region groups share roughly the same exposure to rent and income risk and the analysis above should be correct on average. It nonetheless ignores lagged effects of past choices, as well as (unobserved) heterogeneity within groups. In order to control for the dynamic nature of households' housing choices and (unobserved) heterogeneity, we therefore also need to examine the impact of our key explanatory variables at the household level.

We start by estimating the relationship between a recent mover's probability to rent a home and our two key explanatory variables. Restricting our analysis to recent movers has the advantage to investigate households who have made an active tenure choice. The estimates of a recent mover's probability to rent should therefore avoid the impact of lagged effects on current decisions and more closely reflect equilibrium conditions (Ihlanfeldt, 1981; Boehm et al., 1991). Recent movers might be, however, different to the population regarding to unobserved character- 
istics. Possible consequences for our estimates due to selection bias are discussed below.

We fit pooled probit models for recent movers

$$
P\left(y_{h, t}=1 \mid \rho_{h, t}, \mu(\tau)_{h, t}, \mathbf{x}_{h, t}\right)=\Phi\left(\beta_{0}+\beta_{1} \rho_{h, t}+\beta_{2} \mu(\tau)_{h, t}+\delta \mathbf{x}_{h, t}\right)
$$

where $h$ indexes the household and $t$ the year of the most recent move. $y_{h, t}$ is an indicator variable that takes the value one if the households rents its home and zero otherwise. The diversification potential of renting is captured by $\rho_{h, t}$, which may depend on both the household head's and the spouse's profession. Household's expected remaining residence duration is $\mu(\tau)_{h, t}$, where $\tau$ will be almost always equal to zero because the household just moved. ${ }^{18}$ The vector $\mathbf{x}_{h, t}$ collects socio-economic controls, including a full set of profession and time dummies. Parameter estimates of the probit model in equation (9) are obtained by the method of maximum likelihood. There are two econometric issues associated with the probit model given by equation (9), which need to be addressed.

First, the usual standard errors are invalid because $i$ ) unobserved shocks may be serial correlated if the same household moves more than once during the period under observation and $i i$ ) the use of generated regressors. We therefore use bootstrap standard errors (Efron and Tibshirani, 1993). Based on 200 bootstrap samples from the set of households, we estimate partial effects. The standard deviations across the replications serve as the bootstrap standard errors.

Second, using a sample of recent movers poses the problem of selection on unobservable characteristics. Our estimates can be inconsistent if households' moving decisions are systematically related to unobserved factors that also affect tenure choice (Van de Ven and Van Praag, 1981). For instance, households with inherent preferences to rent are presumably more likely to move despite a large value of $\mu(\tau)_{h, t}$. This is because the substantially lower moving cost if renting allows them

\footnotetext{
${ }^{18}$ As the GSOEP does not always interview households in the same month, the residence duration for some of these households is greater than zero.
} 
to adjust their housing consumption more easily in response to economic shocks. Hence, the estimated coefficient $\beta_{2}$ may be biased towards zero, and away from the prediction of a negative effect. ${ }^{19}$

While the probit analysis of recent movers allows us to control for some of the heterogeneity across households who share a profession and a region, there may be unobserved factors, such as households' risk tolerance, that influence tenure choice. If these factors are independent of the observed explanatory variables, the estimated partial effects can be interpreted as partial effects averaged over the distribution of the unobserved factor. ${ }^{20}$ However, we can not consistently estimate (average) partial effects, if the unobserved factor stochastically depends on observed explanatory variables.

Due to the above mentioned possible problems related to the sample of recent movers, we complement the analysis at the household level by examining the tenure choices of the general population. This will further afford the ability to explicitly control for unobserved heterogeneity.

When estimating the relationship between our key explanatory variables and the probability to rent within the general population, we need to take the (usually) sluggish adjustment of housing choices into account. Our approach to modeling the dynamics of a household's tenure choice is a dynamic random effects probit model

\footnotetext{
${ }^{19}$ Van de Ven and Van Praag (1981) propose a Heckman-type correction for sample selection. While their estimation procedure is formally identified if both the selection equation (modeling the decision to move) and the outcome equation (modeling the decision to rent or buy) include the same set of explanatory variables, the sole source of identification is the nonlinearity of the probit model. A more convenient analysis hinges on appropriate exclusion restrictions. Given the joint nature of moving and tenure choice, in our case these are hard to come by.

${ }^{20}$ To see this, let $c$ be a household-specific unobserved effect. The model of interest is $P(y=$ $1 \mid \mathbf{x}, c)=\Phi(\mathbf{x} \boldsymbol{\beta}+c)$. If the unobserved effect is assumed to be independent of the explanatory variables and normal distributed $c \sim N\left(0, \sigma_{c}^{2}\right)$, the average partial effect of $x_{j}$ is given by $\beta_{j c} \phi\left(\mathbf{x} \boldsymbol{\beta}_{c}\right)$. Here $\beta_{j c}$ denotes the population averaged parameter $\beta_{j c} \stackrel{\text { def }}{=} \beta /\left(1+\sigma_{c}^{2}\right)^{1 / 2}$, which can be consistently estimated by probit of $y$ on $\mathbf{x}$ (see for example Wooldridge (2002)).
} 
of the form

$$
\begin{aligned}
P\left(y_{h, t}=1 \mid y_{h, t-1}, \ldots, y_{h, 0}, \boldsymbol{\rho}_{h}, \boldsymbol{\mu}(\tau)_{h}, \mathbf{x}_{h}, c_{h}\right)= & \Phi\left(\beta_{0}+\beta_{1} \rho_{h, t}+\beta_{2} \mu(\tau)_{h, t}\right. \\
& \left.+\gamma y_{h, t-1}+\mathbf{x}_{h, t} \boldsymbol{\delta}+c_{h}\right)
\end{aligned}
$$

where $h$ indexes the household and $t$ the year. $y_{h, t}$ is an indicator variable that takes the value one if the households rents its home and zero otherwise. The potential state dependence of a household's current tenure choice is captured by the tenure mode in the previous period $y_{h, t-1}$. The household specific term $c_{h}$ stands for all unobserved determinants of tenure choice that are time-invariant. Among these might be factors such as household's risk tolerance or general preferences for either tenure mode. The vectors $\boldsymbol{\rho}_{h}, \boldsymbol{\mu}(\tau)_{h}$, and $\mathbf{x}_{h}$ collect the entire path of the explanatory variables, which are defined above. These variables are assumed to be strictly exogenous once $c_{h}$ is controlled for.

The presence of unobserved heterogeneity in equation (10) leads to two econometric problems (Heckman, 1981; Wooldridge, 2005). First, household specific factors, such as the ones mentioned above, are likely to be correlated with observed characteristics. The degree of risk aversion, for instance, may vary across demographic characteristics. ${ }^{21}$

Second, the household specific factor causes serial dependence in the underlying process of household's tenure mode. Therefore, the first observed tenure mode is stochastically dependent on $c_{h}$. Presumably this is also true when we observe a household at the beginning of its life. This is because the initial rent or buy decision is most likely related to unobserved (risk) preferences as well.

Both of these issues can be addressed by parameterizing the household specific effect conditional on the initial observation and the entire path of all non-redundant

\footnotetext{
${ }^{21}$ Barsky et al. (1997) find risk preferences related to demographics such as age, sex, and religion. A recent study by Sahm (2007) shows that there are few sources of systematic change in risk preference, like age, but substantial and large persistent differences in preferences across individuals that can be explained by demographics.
} 
exogenous variables (Mundlak, 1978; Chamberlain, 1980; Wooldridge, 2005). Modeling the distribution of $c_{h}$ leads to a conditional maximum likelihood approach based on the joint distribution of tenure mode conditional on the initial observation and the exogenous variables. ${ }^{22}$ We implement this approach by parameterizing the distribution of the household specific effect as

$$
c_{h}=\alpha_{0}+\alpha_{1} y_{h, 0}+\alpha_{2} \bar{\rho}_{h}+\alpha_{3} \bar{\mu}(\tau)_{h}+\overline{\mathbf{x}}_{h} \boldsymbol{\alpha}_{4}+a_{h}
$$

where $y_{h, 0}$ is the first observed tenure mode. The bars denote time averages of the observations on the exogenous variables, for instance, $\bar{\rho}_{h}=T^{-1} \sum_{t=1}^{T} \rho_{h, t}$ is the average of the relative riskiness of renting for each household over the sample period. $a_{h}$ is assumed to be independent of the exogenous variables and the initial tenure mode, and distributed normal $a_{h} \mid\left(y_{h, 0}, \boldsymbol{\rho}_{h}, \boldsymbol{\mu}(\tau)_{h}, \mathbf{x}_{h}\right) \sim N\left(0, \sigma_{a}^{2}\right)$.

Under these assumptions, the probability to rent (given $\left(y_{h, t-1}, \ldots, y_{h, 0}, \boldsymbol{\rho}_{h}\right.$, $\left.\left.\boldsymbol{\mu}(\tau)_{h}, \mathbf{x}_{h}, a_{i}\right)\right)$ follows a probit model with outcome probability $\Phi\left(\beta_{0}+\beta_{1} \rho_{h, t}+\beta_{2} \mu(\tau)_{h, t}+\gamma y_{h, t-1}+\mathbf{x}_{h, t} \boldsymbol{\delta}+\alpha_{1} y_{h, 0}+\alpha_{2} \bar{\rho}_{h}+\alpha_{3} \bar{\mu}(\tau)_{h}+\overline{\mathbf{x}}_{h} \boldsymbol{\alpha}_{4}+a_{h}\right)$. The joint density, integrated against the $\mathrm{N}\left(0, \sigma_{a}^{2}\right)$ distribution, has exactly the same structure as the conditional likelihood of the random effects probit model. Parameter estimates are therefore obtained by standard conditional maximum likelihood methods (see for example Wooldridge (2002)). However, it should be noted that we can only include the averages of time-varying variables in equation (11). This is because correlation of constant variables with $c_{h}$ and their impact on the probability to rent can not be discriminated.

In order to assess the effect of our key explanatory variables on the probability to rent, we compute average partial effects. Average partial effects evaluate the

\footnotetext{
${ }^{22}$ The usual way to account for the initial condition problem in dynamic nonlinear panel models is to model the distribution of the initial observation conditional on the unobserved effect and the exogenous variables, see for example Heckman (1981). The approach followed here serves the same purpose, but leads to a much simpler estimator of the parameters and average partial effects. A detailed discussion can be found in Wooldridge (2005).
} 
impact of a change in an explanatory variable on the outcome probability averaged over the distribution of the unobserved effect. Wooldridge (2005) shows that the expected outcome probability with respect to the distribution of $c_{h}$ can be consistently estimated by

$$
\begin{gathered}
N^{-1} \sum_{h=1}^{N} \Phi\left(\widehat{\beta}_{a 0}+\widehat{\beta}_{a 1} \rho+\widehat{\beta}_{a 2} \mu(\tau)+\mathbf{x} \widehat{\boldsymbol{\delta}}_{a}+\widehat{\gamma}_{a} y_{t-1}+\widehat{\alpha}_{a 1} y_{h 0}+\widehat{\alpha}_{a 2} \bar{\rho}_{h}\right. \\
\left.+\widehat{\alpha}_{a 3} \bar{\mu}(\tau)_{h}+\widehat{\boldsymbol{\alpha}}_{a 4}^{\top} \overline{\mathbf{x}}_{h}\right)
\end{gathered}
$$

where the subscript $a$ denotes the population averaged parameters, that is the original parameter estimate multiplied by $\left(1+\sigma_{a}^{2}\right)^{-1 / 2} . N$ is the number of all observations in all time periods. The explanatory variables $\rho, \mu(\tau), \mathbf{x}$, and $y_{t-1}$ are set to fixed values of interest. We then obtain average partial effects by computing changes or derivatives of expression (12) with respect to the variable under scrutiny.

Standard errors for the average partial effects are estimated from a panel (or block) bootstrap. A block consists of the observations on an individual household as a whole and covers at least 1 year and at most 20 years. For each block size (measured in years), we resample the same number of households as there are in the initial sample. This procedure preserves the total sample size as well as the pattern of unbalancedness in our data. We consider 200 replications from the set of blocks and based on the resulting bootstrap sample estimate average partial effects. The standard deviations across the replications serve as our bootstrap standard errors.

There are two econometric issues associated with the dynamic correlated random effects probit model given by equations (10) and (11), which need to be addressed. First, identification of the impact of variables with limited variation within households on the probability to rent may be hard to establish. In particular, the relative riskiness of renting is almost always time constant inducing severe multi-collinearity between $\rho_{h, t}$ and $\bar{\rho}_{h}$. Hence, the average of this variable may turn out to be significant, while the direct effect is insignificant. To examine this, we therefore estimate two specifications of the correlated random effects model: $i$ ) a model with $\bar{\rho}_{h}$ and 
ii) a model without it. In addition we report pooled probit estimates of equation (10) that ignore any correlation between $c_{h}$ and the explanatory variables.

Second, the maximum likelihood estimator for the dynamic correlated random effects model hinges on the strict exogeneity assumption of the explanatory variables. This assumption implies that future values of any explanatory variables can not be related to household's current tenure mode. However, in our case, misspecification may arise from feedback effects of home-ownership to a household's expected remaining residence duration. We test for exogeneity of this variable, by including future values of $\mu(\tau)_{h, t}$ into the model. If the current mean residual time is strictly exogenous, we should find the future values to be insignificant (see for example Wooldridge (2002)).

\section{Results}

\subsection{Results at the profession group level}

We have 3925 observations at the profession-group level. Summary statistics for the variables at this level are given in the third column of Table 1. The statistics are quite similar to the statistics at the household level, but can differ, because groups size is ignored. Between 1984 and 2004, the average rental share across professionregion cells was about $54 \%$. There is, however, substantial variation in rental shares which is largely attributable to cross sectional differences across professions and regions.

Table 4 reports estimated partial effects obtained from ordinary least squares regressions of equation (8). The partial effects are evaluated at sample averages of mean profession-group characteristics (see column 3 of Table 1). The first specification in Table 4 gives the estimation results from a regression that does not control for differences in the composition of households across profession-region groups. The 
second specification adds the socio-economic control variables. Both specifications include a full set of time dummies and profession dummies.

[Table 4 about here.]

As expected, the impact of the profession-region specific relative riskiness of renting, $\rho_{p r}$, on rental shares is positive. The share of renters of professions living in regions with a higher diversification potential of renting are larger compared to regions where renting does not allow to diversify some of the profession-specific income risk. This effect is statistically significant in both specifications. To gauge the magnitude of the diversification effect, we multiply the estimated partial effects by a one standard deviation of $\rho_{p r}$. Such an increase in the diversification potential implies that the average household's net income variance if renting (holding the profession-specific income variance constant) decreases by approximately 10 percent. Using the estimate from the first specification, this risk reduction yields an increase of rental shares by $1.4 \%$. The magnitude of the effect, however, is smaller after including the socio-economic controls. The same increase of $\rho_{p r}$ is accompanied by an increase in rental shares of $1.0 \%$ percentage points using the estimate from the second specification.

The impact of mobility needs, $\bar{\mu}(\tau)_{p r, t}$, has the expected negative sign in both specifications. The share of renters is significantly smaller in profession-region groups that are characterized by on average longer expected remaining residence durations. This result, of course, not only reflects homeowners' exposure to resale price risk, but also the substantially lower transactions cost of changing residence if renting. Increasing the expected duration by one year implies a decrease of rental shares by $2.7 \%$. Given the positive correlation between demographics, such as household size (see Table 8 in the Appendix) and the expected remaining duration, it is not surprising that the mobility effect is smaller in the second specification. Here the same increase in $\bar{\mu}(\tau)_{p r, t}$ yields a decrease of rental shares by $1.6 \%$. 
The signs of the estimated partial effects of the socio-economic characteristics in Specification 2 of Table 4 are throughout reasonable. The average yearly professional income has a negative, yet statistically insignificant, effect on rental shares. The ratio of regional house prices to yearly household income and the proportions of households with no financial assets, on the other hand, have a positive and significant effect on rental shares. These effects are consistent with the interpretation as presence of credit constraints that prevent households from buying a home.

Demographic characteristics, like household size, number of children, and marital status, have the expected negative impact on the proportion of renters. Notably the proportion of households with a foreign head increases rental shares. These effects are statistically significant at the usual levels. The impact of household head's gender and age on rental shares, on the other hand, are indistinguishable from zero. While economic theory does not suggest any particular influence of the former variable, identification of the latter is aggravated by the rather small variation of household head's average age across profession-region groups.

Surprisingly, the estimated effect of household head's education is positive. If formal education is a proxy for household's (future) earning potential, we rather expect the propensity to rent to decline with this variable. While this line of reasoning especially holds at the beginning of household (adult) lives (Gyourko and Linneman, 1997), the static nature of the rental share regressions may distort our estimation results. Below we find the expected negative impact of household head's education on the probability to rent for individual households.

We conclude that the results in Table 4 provide evidence for the proposed effect of income risk and mobility needs of different professions on households' tenure choice. The aggregate level analysis, however, has its limitations. First, households within profession-region groups are heterogenous with regard to observed and unobserved characteristics that may influence tenure mode choice. Second, the rental share regressions are static in nature and ignore the dynamic aspect of the tenure choice. 
We cope with these limitations next by using data at the household level.

\subsection{Results at the household level}

We first present results for recent movers. Recent movers are households who have moved into their current residence between two survey waves. Since the GSOEP does not provide information on a change of residence in 1984, we use observation from 1985 to 2004. Summary statistics for the recent mover sample are provided in the last column of Table 1 . We observe 5820 recent movers comprising, due to multiple moves, 3364 individual households. Recent movers are different from the relevant general population as represented in the second column. The socioeconomic characteristics suggest that recent movers are in the early stage of their life-cycle. Compared to the average household in the main sample, recent movers earn less income and have accumulated less assets. They are on average also younger, of smaller size, and comprise less families (with less children). Moreover, a recent mover is also more likely to be renter.

Table 5 reports estimated partial effects from the pooled probit model given in equation (9). The partial effects are evaluated at sample averages of household characteristics (see the last column of Table 1). The first specification in Table 5 present estimation results when only the two key explanatory variables and time and

profession dummies are included. The socio-economic control variables are added in the second specification.

[Table 5 about here.]

The estimated partial effect of the household-specific diversification potential of renting, $\rho_{p r, t}$, is again positive for both specifications and statistically significant. Thus, the probability to rent of the average recent mover decreases with the household's net income risk if renting. Notably, the magnitude of the diversification potential effect is of a similar magnitude as in the rental share regressions. Multiplying the 
estimated partial effect with a one standard deviation increase of $\rho_{p r, t}$ (implying a larger diversification potential if renting) by roughly $10 \%$ yields an increase in the probability to rent by about $1.2 \%$.

The impact of household's expected remaining residence duration, $\mu(\tau)_{h, t}$, on the probability to rent is negative and statistically significant. Considering the estimated partial effect in the first specification, an increase of the expected duration by one year yields a decrease of the probability to rent by $2.8 \%$. While the magnitude of this effect is of similar size compared to the results from the rental share regressions, the estimated mobility effect becomes much smaller after controlling for the observed heterogeneity across households. In the second specification, the same increase of $\mu(\tau)_{h, t}$ decreases the probability to rent by only $0.6 \%$. Given the discussion in the previous section, this result is most likely attributable to the selection of the sample on the basis of active moving decisions.

The estimated partial effects of the socio-economic control variables in the second specification in Table 5 are reasonable and of similar magnitude as at the aggregate level (see Table 4). As in all regressions before, the probability to rent increases significantly with the ratio of average house prices to household income, as well as the absence of financial asset holdings. Unlike to the rental share regressions, the influence of yearly income is now statistically significant. As expected, the greater sample variation in this variable allows us to identify a negative impact of this variable on the probability to rent. Given that the 'no assets' and the 'price to income' variables already control for credit constraints, the income variable controls for the differential tax treatment. Owner's imputed rents are not taxed, which is the more valuable the higher the marginal tax rate and thus the higher owner's income.

The demographic control variables, like household size, marital status, number of children, and foreign household heads, have a statistically significant influence on the probability to rent. Compared to their effect in the rental share regressions, the magnitude of these effects are only slightly smaller. Notably, the age and the 
education of household head have the expected negative influence on household's probability to rent. It is, however, not clear if the significant age effect mirrors true life cycle effects like wealth accumulation. This is because there may be indirect age effects due to correlation between this variable and unobserved factors, such as risk tolerance.

The last specifications are fitted to all observations in our main sample as summarized in 1. Table 6 reports average partial effects (APE) from pooled probit and correlated random effects estimates of equation (10). In the case of the pooled probit model, we ignore any correlation between the explanatory variables and the unobserved effect. We interpret the estimated coefficients as population averaged parameters, from which we directly compute the APEs (see for example Wooldridge (2002)). The correlated random effects model parameterizes the unobserved effect as a function of the within-household averages of the time-varying explanatory variables and a vector of dummy variables to represent the first observed tenure mode. We compute the APEs based on expression (12). Both the APEs of the pooled probit and correlated random effects model are evaluated at sample averages of household characteristics (see the second column of Table 1).

In the first specification of the pooled probit model, we only include our two key explanatory variables, the initial and lagged tenure mode, time dummies, and profession dummies. ${ }^{23}$ In the second pooled probit specification, the socio-economic control variables are added. The remaining results are for four different specifications of the correlated random effects model: The first two, specifications 3 and 4 in Table 6 , allows for correlation between the time-average of the relative riskiness of renting, $\bar{\rho}_{h}$, and the unobserved effect. The last two leave $\bar{\rho}_{h}$ out. In the reported results, we further drop the time-averages of gender and nationality of household heads. These variables are almost always time-constant. In order to allow panel attrition to be correlated with the unobserved effect, we also include a full set of dummy variables

\footnotetext{
${ }^{23}$ The initial tenure mode, $y_{h, 0}$, is included, because $y_{h, 0}$ must be correlated with the unobserved factor $c_{h}$ if present.
} 
representing the years a household is not observed.

\section{[Table 6 about here.]}

In all four specifications of the correlated random effects model the estimated variance of the unobserved effect is substantial. A likelihood ratio test of the null hypothesis that $\theta \stackrel{\text { def }}{=} \sigma_{a}^{2} /\left(\sigma_{a}^{2}+1\right)$ is zero is always rejected. ${ }^{24}$ Furthermore, controlling for unobserved effects improves the fit of the model, as evidenced by the change in the $\log$ likelihood and Pseudo $R^{2}$. Notably there is still much unobserved heterogeneity even after explicitly considering socio-economic differences across households. Without controls, $a_{h}$ accounts for approximately $53 \%$ of the unexplained error variance (specifications 3 and 5), compared to $48 \%$ after including demographics (Specifications 4 and 6 ). There is thus strong evidence that unobserved factors influence households' tenure choices.

Before we turn to the estimated effects of our key explanatory variables, it is of interest to discuss how past tenure choices influence current choices. The impact of the lagged tenure mode, $y_{h, t-1}$, is positive and significant in all specifications. Therefore, occupancy of either tenure mode highly affects current housing choices. It is striking that, comparing the correlated random effects estimates to the pooled probit estimates, the magnitude of the APEs are substantially smaller. This result suggests that the coefficient on $y_{h, t-1}$ in the pooled probit estimates has picked up the effect of unobserved household characteristics. However, even after controlling for unobserved effects, the degree of state dependence is substantial. Changing the tenure mode from owner to renter increases a household's probability to rent it's home in the following year by approximately $58 \%$ in columns three through six.

Even after controlling for the strong state dependence of households' tenure choices (and unobserved heterogeneity) the estimated effect of the household specific

\footnotetext{
${ }^{24}$ Since the variance of the idiosyncratic error in the underlying latent variable model is unity, $\theta$ measures the relative importance of $\sigma_{a}^{2}$. If $\theta$ equals zero the unobserved effect is unimportant and random effects estimates are not different from pooled probit estimates.
} 
diversification potential, $\rho_{h, t}$, has a positive sign. The probability to rather rent then buy a home increases with the diversification potential measure in all specifications. The effect, however, is indistinguishable from zero in both correlated random effects specifications A (Specification 3 and 4). This result can be explained by the severe collinearity between $\rho_{h, t}$ and its within household time average $\bar{\rho}_{h, t}$. As expected, identification of the true effect of $\rho_{h, t}$ on the probability to rent and its correlation with the unobserved effect is aggravated, because $\rho_{h, t}$ only varies over time when household members change their profession or the household moves to a new region.

Given that this variable is not correlated with unobserved household characteristics, we can largely confirm the results from the rental share regressions and probit estimates for recent movers. ${ }^{25}$ Whereas the estimated APE of $\rho_{h, t}$ on the probability to rent is only weakly significant (with a p-value of 0.125 ) in Specification 5, the income risk effect is statistically significant after controlling for socio-economic differences across households. Multiplying the estimated APE of 0.121 in Specification 6 with a one standard deviation increase of $\rho_{h, t}$, which implies an increase of the diversification potential if renting by roughly $10 \%$, increases the probability to rent by $1.2 \%$.

Turning to the impact of mobility needs, we find that the estimated APEs of households' expected remaining residence duration, $\mu(\tau)_{h, t}$, have the expected negative sign in all six specifications. The mobility effect is throughout statistically significant. In our preferred model specification, the correlated random effects specification (B) with socio-economic controls (Specification 6), a one year increase in $\mu(\tau)_{h, t}$ decreases the probability to rent by about $1.4 \%$. Notably, the magnitude of the estimated APEs only slightly vary across estimation methods and model specifications. Moreover, the size of the mobility effect is throughout comparable to the magnitude of partial effects which we have found in the rental share regressions (see

\footnotetext{
${ }^{25}$ While Guiso and Paiella (2008) show that the presence of uninsurable income risk can influence households' risk tolerance, our use of a relative risk measure should eliminate such correlations if they exist.
} 
Table 4).

The estimated impact of the socio-economic controls on the probability to rent have reasonable directions in the specifications where they are included. After allowing for correlation between these variables and the unobserved effect, however, the APEs of most controls are indistinguishable from zero. Exceptions are income, the ratio of average house prices to household income, household size, and foreign household heads, which all have the expected influence on the probability to rent. The insignificant APEs are likely to be due to two reasons: First, some of the variables, such as age, affect tenure choice indirectly through their correlation with unobserved factors. Second, in some cases the rather time-constant nature of variables, like education and marital status, severely aggravates identification.

\subsection{Robustness checks}

We checked the sensitivity of our results by fitting the models to different subsamples and by using specification tests.

First, we investigated whether the inclusion of potentially credit constrained households distort the estimated effects of our key explanatory variables. Households who are credit constraint, in the sense that their lifetime resources are sufficient to buy a home, but current wealth does not suffice the down-payment requirement to obtain bank financing, are renters by default. Under the presumption that these households live in subsidized social housing dwellings, we re-estimated the three empirical models using only households operating in the private sector. The main results in Tables 4, 5, and 6 remained unchanged. The GSOEP does not provide information if initially subsidized social rental dwellings have been turned into privately rented dwellings during the course of time, so the above strategy may exclude too many households. ${ }^{26}$ Therefore, we also conducted the analysis restricted

\footnotetext{
${ }^{26}$ Most social rental dwellings where constructed using subsidized loans, which bind landlords to accept eligible households and also curtails the rent they can command. After 30 years or so,
} 
to households who report at least some resources that may be utilized as a downpayment for an owner-occupied home. In particular, we excluded households with no financial asset holdings (besides saving accounts). Again the main results in the tables remained qualitatively unchanged.

Second, we restricted the analysis to households whose head is of German origin. As households with foreign heads might have quite different planning horizons, their inclusion could also distort our results. In particular, foreign households may expect to re-emigrate to the country of their origin after retirement, and thus do not invest in owner-occupied housing regardless of the risk aspects under consideration. The main results in the tables remained qualitatively unchanged.

Third, we tested for the endogeneity of the explanatory variables in the dynamic correlated random effects model as explained above. We found that the coefficient on the lead of the mean residual time is not distinguishable from zero, which provides justification for the strict exogeneity assumption we make in our analysis.

\section{Conclusion}

In this study we have empirically investigated the impact of professional career decisions and their associated income risk and mobility needs on the tenure choice of German households. Economic theory suggests that members of professions whose income comoves strongly with regional rental prices should prefer to rent their home. Then periods of declining income are accompanied by decreasing rents, allowing to smooth consumption of non-housing goods. Given homeowners exposure to the resale price risk of their house and the substantially larger transactions cost of changing residence, members of professions requiring high mobility should also prefer to rent.

We find empirical support for these two impacts of professional career decisions on households' tenure choice. We find for profession-region groupings that group's however, the commitment is no longer binding and dwellings can be rented at market prices. 
rental share is higher if renting smoothes net income and if the expected residence duration of group members is short. Using data on both recent movers and the general population, we confirm these key results at the household level. Even after controlling for the substantial state dependence of households' tenure choices and unobserved heterogeneity, we find that income risk and mobility needs affect the propensity to rent as expected.

The empirical findings of our study are particulary interesting with respect to households' risk management opportunities. Starting with Shiller's (1993) initial contribution, a vast amount of literature has focussed on new financial instruments that allow homeowners to insure against house price fluctuations as part of an integrated risk management approach. However, a well-functioning private rental market works in the same direction and can provide risk diversification benefits to households. Renting allows households to separate the use component from the investment component and thus provides valuable flexibility. The empirical results of our study indicate that households exploit these benefits if present.

Our analysis focussed only on the residential user side. Investors, i.e., landlords, were treated as absent. However, for many investors investment in rental apartments might be a welcome extension of the investable asset universe. It might be worthwhile to study the welfare contribution of a well-functioning private rental market in a general equilibrium context. While the exact welfare contribution is by no means obvious, it is natural to expect that preferential treatment of one tenure mode over the other should be avoided by policy makers. 


\section{A Appendix}

\section{A.1 Cluster Analysis}

Our cluster analysis uses the observed transitions between industry-occupation categories in the GSOEP to delineate profession groups. Let $i$ denote a occupationindustry group and $p_{i j}$ the probability of a person to belong to this group conditional on being a member of group $j$ in the previous period. These initial transition probability are estimated by

$$
p_{i j}=\frac{\sum_{t \in T} N_{i, t \mid j, t-1}}{\sum_{t \in T} N_{i, t}},
$$

where $N_{i, t \mid j, t-1}$ is the number of persons employed in group $i$ in period $t$ conditional on being employed in group $j$ in period $t-1$. $N_{i, t}$ denotes the total number of persons employed in group $i$ in period $t$.

We specifically use observations on 122,978 employed individuals (household heads and spouses) who live in West-Germany and 18-65 years of age and have been in the GSOEP for at least two years to estimate the elements of the initial transition matrix. The initial occupation-industry groups are assigned to each individual according to the ISCO-88 1-digit and the NACE Rev.1 1-digit classification of occupations and industries, respectively. ISCO-88 covers 9 main occupations. NACE covers 17 main industries from which three industries are not observed. Furthermore, two initial occupation-industry groups are not observed (see Table 2).

The transition matrix between these 124 industry-occupation groups is the data matrix from which we build the profession groups. In particular, we use a K-Medians cluster algorithm that starts from a given partition of the initial groups and proceeds by exchanging elements between groups until a certain score is optimized (see e.g. Rencher, 2002). Here, we experimented with a number of initial profession groups that we have found by a first step agglomerative (weighted-average linkage) cluster algorithm. Both, dendograms from this first step analysis and a careful inspection of the allocation of industries and occupations to professions let us choose 14 profession 
groups.

[Table 7 about here.]

Table 7 reports the estimated transition probabilities between these 14 profession groups. The cluster analysis was quite successful in assigning industry and occupation categories to stable professions. The diagonal elements of the matrix, that is the transition probabilities within professions, are almost always above 80 percent. The lowest within transition probability is 79 percent, the highest within transition probability is 94 percent. The off-diagonal elements, that is the transition probabilities between professions is almost always lower than 3 percent. The lowest between transition probability is virtually 0 percent, the highest between transition probability is about 10 percent.

\section{A.2 Survival Analysis}

We define $\tau_{i}$ to be the duration of the $i$-th households' residence spell, that is the elapsed duration since the household has moved into it's current residence. A spell is completed if the household moves to a new residence or dissolves. Here dissolving household are the result of emigration, death, or disbandment for other reasons. Otherwise spells are defined to be right-censored.

In order to estimate the unknown parameters in equation (6), we employ the following linear regression model for censored data:

$$
\ln \left(\tau_{i}\right)=\mathbf{x}(\tau)_{i} \boldsymbol{\beta}+\varepsilon_{i}
$$

where the vector $\mathbf{x}(\tau)_{i}$ collects (possibly) time-varying household characteristics at time $\tau$ and the error term is standard normal distributed $\varepsilon_{i} \sim N\left(0, \sigma^{2}\right)$. In our preferred model specification we include age, age squared of the household head at the beginning of the spell and dummy variables for three different household sizes, dual-earner households, household heads' marital status, and household heads' 
gender in $\mathbf{x}(\tau)_{i}$. To capture profession specific impacts on households' mobility, we further include dummy variables representing the household head's profession. The reference category are household heads who are not in the labor force. We further include time dummies for the beginning of the residence spells in $\mathbf{x}(\tau)_{i}$.

We fit equation (14) by the method of maximum-likelihood using a flow sample of households' residence spells (see for example Lancaster (1990)). This sample is extracted from the GSOEP for the period 1985 to 2003. Here, a new observation on a residence spell enters our sample when a household moves to a new residence or is newly formed in the year under consideration. The 1984 and 2004 survey waves are excluded for the following reasons. First, the GSOEP does not identify a households moving status in 1984. Second, Observations in 2004 are right-censored by definition. Note that we though allow for multiple spells of the same household. In total we observe 8052 residence spells. Of these 4438 are completed. The remaining spells are right-censored.

[Table 8 about here.]

Table 8 reports maximum likelihood estimates of equation (14). The coefficients on the demographic control variables are statistically significant and have reasonable signs. The age of household heads, for instance, has a hump-shaped profile: The expected length of residence spells increases up to an age of 35 years and subsequently decreases. The coefficients on the profession dummies, on the other, are only partly significant. A Wald test of the joint significance, however, rejects the null hypotheses that the coefficients are jointly zero. Thus, providing evidence that the profession of the household head affects residential mobility. 


\section{References}

Amemiya, T.: 1981, Qualitative response models: A survey, Journal of Economic Literature 19, 1483-1536.

Barsky, R. B., Juster, F. T., Kimball, M. S. and Shapiro, M. D.: 1997, Preference parameters and behavioral heterogeneity: An experimental approach in the health and retirement study, Quarterly Journal of Economics 112, 537-579.

Berkovec, J. and Fullerton, D.: 1992, A general equilibrium model of housing, taxes, and portfolio choice, Journal of Political Economy 100, 390-429.

Boehm, T. P., Herzog, H. W. and Schlottmann, A. M.: 1991, Intra-urban mobility, migration, and tenure choice, Review of Economics and Statistics 73, 59-68.

Chamberlain, G.: 1980, Analysis of covariance with qualitative data, Review of Economic Studies 47, 225-238.

Cunha, F. and Heckman, J. J.: 2007, The evolution of inequality, heterogeneity and uncertainty in labor earnings in the U.S. economy, Technical Report 13526, National Bureau of Economic Research.

Davidoff, T.: 2006, Labor income, housing prices, and homeownership, Journal of Urban Economics 59, 209-235.

Diaz-Serrano, L.: 2005, Labor income uncertainty, skewness and homeownership: A panel data study for Germany and Spain, Journal of Urban Economics 58, 156176.

Dickens, W. T.: 1990, Error components in grouped data: Is it ever worth weighting?, The Review of Economics and Statistics 72, 328-333.

Efron, B. and Tibshirani, R. J.: 1993, An Introduction to the Bootstrap, Vol. 57 of Monographs on Statistics and Applied Probability, Chapman and Hall, New York. 
Guiso, L. and Paiella, M.: 2008, Risk aversion, wealth, and background risk, Journal of the European Economic Association 6, 1109-1150.

Gyourko, J. and Linneman, P.: 1997, The changing influence of education, income, family structure, and race on homeownership by age over time, Journal of Housing Research 8, 1-25.

Haurin, D. R. and Gill, H. L.: 2002, The impact of transaction costs and the expected length of stay on homeownership, Journal of Urban Economics 51, 563-584.

Heckman, J. J.: 1981, The incidental parameters problem and the problem of initial conditions in estimating a discrete time discrete data stochastic process, in C. Manski and D. McFadden (eds), Structural Analysis of Discrete Data with Econometric Applications, MIT Press, Cambridge MA.

Henderson, J. V. and Ioannides, Y. M.: 1989, Dynamic aspects of consumer decisions in housing markets, Journal of Urban Economics 26, 212-230.

Hubert, F.: 1998, Private rented housing in Germany, Journal of Housing and the Built Environment 13, 205-232.

Ihlanfeldt, K. R.: 1981, An empirical investigation of alternative approaches to estimating the equilibrium demand for housing, Journal of Urban Economics 9, 97105.

Kan, K.: 2000, Dynamic modeling of housing tenure choice, Journal of Urban Economics 48, 46-69.

King, M. A.: 1980, An econometric model of tenure choice and demand for housing as a joint decision, Journal of Public Economics 14, 137-159.

Kirchner, J.: 2007, The declining social rental sector in Germany, European Journal of Housing Policy 7, 85-101.

Lai, C.-D. and Xie, M.: 2006, Stochastic Ageing and Dependence for Reliability, Springer, New York. 
Lancaster, T.: 1990, The Econometric Analysis of Transition Data, number 17 in Econometric Society Monographs, Cambridge University Press, Cambridge.

Martin, J. P.: 1996, Measure of replacement rates for the purpose of international comparison: A note, OECD Economic Studies 26, 99-115.

Mundlak, Y.: 1978, On the pooling of time series and cross section data, Econometrica 46, 69-85.

Neal, D.: 1995, Industry-specific human capital: Evidence from displaced workers, Journal of Labor Economics 13, 653-677.

Ortalo-Magné, F. and Rady, S.: 2002, Tenure choice and the riskiness of non-housing consumption, Journal of Housing Economics 11, 266-279.

Rencher, A. C.: 2002, Methods of Multivariate Analysis, 2 edn, John Wiley and Sons, Hoboken, NJ.

Rosen, H. S.: 1979, Housing decisions and the U.S. income tax, Journal of Public Economics 11, 1-23.

Rosen, H. S. and Rosen, K. T.: 1980, Federal taxes and homeownership: Evidence from time series, Journal of Political Economy 88, 59-75.

Rosen, H. S., Rosen, K. T. and Holtz-Eakin, D.: 1984, Housing tenure, uncertainty, and taxation, Review of Economics and Statistics 66, 405-416.

Sahm, C.: 2007, How much does risk tolerance change?, Finance and Economics Discussion Series 2007-66, The Federal Reserve Board.

Shiller, R. J.: 1993, Macro Markets: Creating Institutions for Managing Society's Largest Economic Risks, Oxford University Press, Oxford, U.K.

Shiller, R. J. and Schneider, R.: 1998, Labor income indices designed for use in contracts promoting income risk management, Review of Income and Wealth 44, 163182. 
Sinai, T. and Souleles, N. S.: 2005, Owner-occupied housing as a hedge against rent risk, Quarterly Journal of Economics 120, 763-789.

Tomann, H.: 1990, The housing market, housing finance and housing policy in West Germany: Prospects for the 1990s, Urban Studies 27, 919-930.

Van de Ven, W. P. M. M. and Van Praag, B. M. S.: 1981, The demand for deductibles in private health insurance: A probit model with sample selection, Journal of Econometrics 17, 229-252.

White, M. J. and White, L. J.: 1977, The tax subsidy to owner-occupied housing: Who benefits?, Journal of Public Economics 3, 111-126.

Wooldridge, J. M.: 2002, Econometric Analysis of Cross Section and Panel Data, MIT Press, Cambridge, M.A.

Wooldridge, J. M.: 2005, Simple solutions to the initial conditions problem in dynamic, nonlinear panel data models with unobserved heterogeneity, Journal of Applied Econometrics 20, 39-54. 
Table 1: Summary statistics by household sample. Mean of variables. Standard deviations of the variables are in square brackets. Yearly labor income is income of household head in real (2000) Euros, deflated by the German CPI excluding housing services. Priceincome ratio is the ratio of the mean price of a single-family dwelling of average quality and yearly household income. Data for regional house prices are provided by the Ring Deutscher Makler (RDM). Relative riskiness of renting is calculated according to equation (4). In column 2 and column 2 this variable is allowed to depend on both the household head's and spouse's profession. Mean residual time is calculated according to equation (6).

\begin{tabular}{lccc}
\hline \hline & $\begin{array}{c}\text { Unbalanced } \\
\text { household panel } \\
1984-2004\end{array}$ & $\begin{array}{c}\text { Profession-region } \\
\text { cells } \\
1984-2004\end{array}$ & Recent movers \\
& 0.531 & 0.536 & $1985-2004$ \\
\hline Renter & 47.867 & {$[0.174]$} & 0.782 \\
Age & {$[9.943]$} & 41.474 & 34.492 \\
Education & 11.285 & {$[4.946]$} & {$[10.415]$} \\
Household Size & {$[2.687]$} & {$[1.892$} & 11.676 \\
Yearly labor income (0000) & 3.035 & 2.816 & {$[2.766]$} \\
& {$[1.409]$} & {$[0.648]$} & 2.367 \\
House price/Hh. income & 26.015 & 29.120 & {$[1.259]$} \\
& {$[19.951]$} & {$[9.541]$} & {$[17.265]$} \\
Female & 11.508 & 9.966 & 14.375 \\
& {$[9.055]$} & {$[4.218]$} & {$[10.773]$} \\
Kids & 0.161 & 0.285 & 0.384 \\
Married & & {$[0.264]$} & \\
No assets & 0.569 & 0.500 & 0.339 \\
& & {$[0.234]$} & \\
Foreigner & 0.771 & 0.654 & 0.451 \\
Relative riskiness & 0.097 & {$[0.227]$} & \\
Mean residual time & & 0.079 & 0.143 \\
Number of observation & {$[0.129]$} & \\
\hline \hline
\end{tabular}


Table 2: Allocation of industries and occupations to profession groups. Table presents 14 profession clusters. Occupation categories are the 9 main occupations according to ISCO-88 classification, which comprises the following occupations: ISCO 1 Legislators, senior officials and managers, ISCO 2 Professionals, ISCO 3 Technicians and associate professionals, ISCO 4 Clerks, ISCO 5 Service workers and shop and market sales workers, ISCO 6 Skilled agricultural and fishery worker, ISCO 7 Craft and related trades workers, ISCO 8 Plant and machine operators and assemblers, ISCO 9 Elementary occupations. Industry categories are the 14 main sectors according to NACE, Rev. 1.1 classification, which comprises the following sectors: $N A C E A$ Agriculture, hunting and forestry, $N A C E B$ Fishing, $N A C E C$ Mining and quarrying, NACE $D$ Manufacturing, NACE E Electricity, gas and water supply, NACE F Construction, NACE G Wholesale and retail trade, NACE H Hotels and restaurants, NACE I Transport, storage and communication, NACE J Financial intermediation, NACE $K$ Real estate, renting and business activities, $N A C E L$ Public administration and defence, $N A C E M$ Education, $N A C E N$ Health and social work, $N A C E O$ Other community, social and personal service activities, NACE P Activities of households, $N A C E Q$ Extra-territorial organizations and bodies.

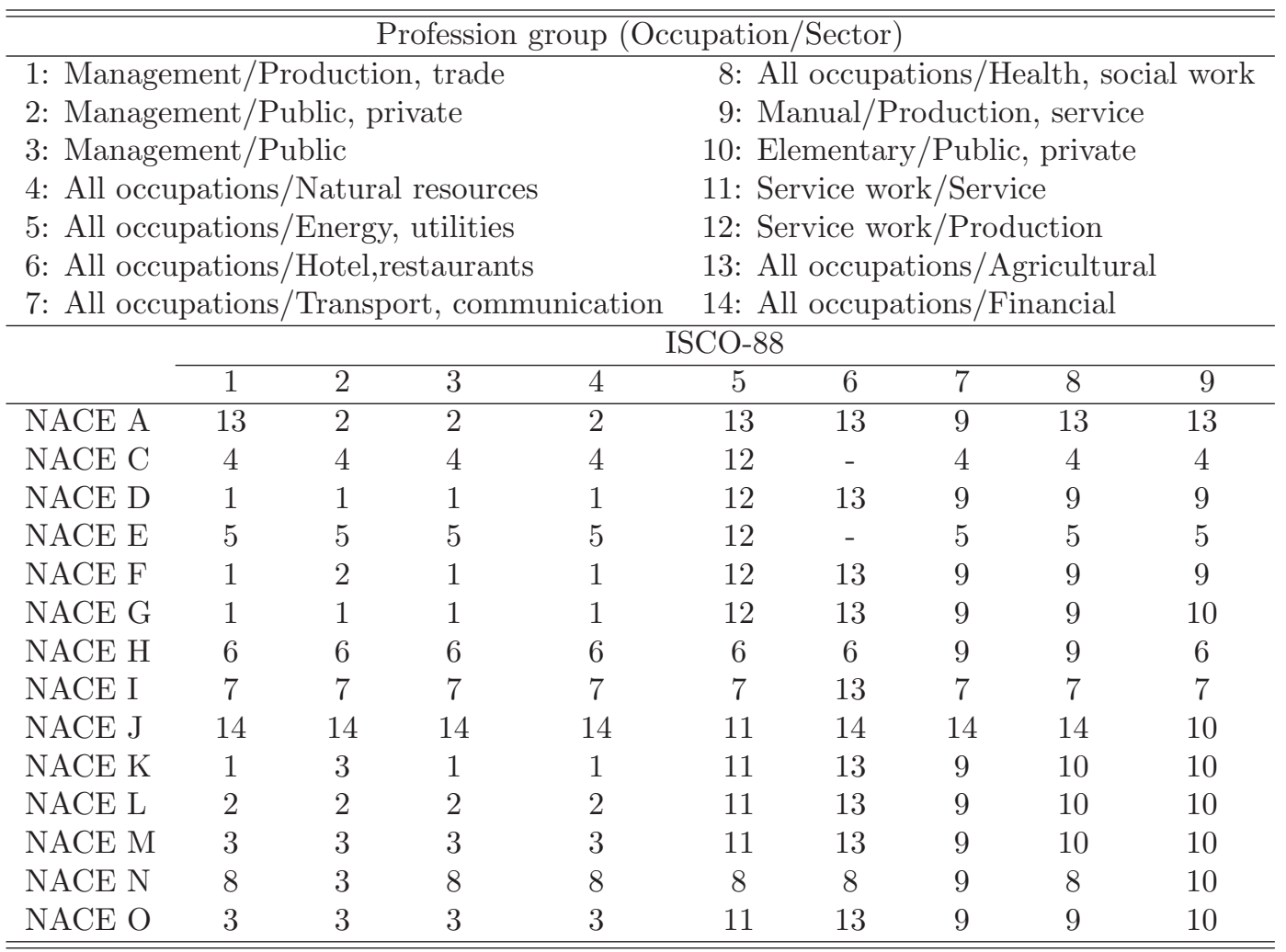


Table 3: Summary statistics of key variables. Key variables are at profession and NUTS2 level. Mean of variables. Standard deviations are in square brackets. Rent growth and income growth, and the standard deviations of rent and income growth are computed from constant-quality rent and income indices. Relative riskiness of renting, $\rho_{p r}$, is calculated according to equation (4). Mean residual time is calculated according to equation (6). Median rent level, median income level, and the proportion of renters are estimated from GSOEP wave 1995. All euro values are in real (2000) euros, deflated by the German CPI excluding housing services.

\begin{tabular}{|c|c|c|c|c|}
\hline & \multicolumn{2}{|c|}{ Profession groups } & \multicolumn{2}{|c|}{ Regions } \\
\hline & 1984-2004 & 1995 & 1984-2004 & 1995 \\
\hline Real income growth & $\begin{array}{c}0.012 \\
{[0.036]}\end{array}$ & & & \\
\hline S.d. of real income growth & $\begin{array}{c}0.034 \\
{[0.013]}\end{array}$ & & & \\
\hline Median of $\rho_{p r}$ & & $\begin{array}{c}0.988 \\
{[0.034]}\end{array}$ & & \\
\hline S.d. of $\rho_{p r}$ & & $\begin{array}{c}0.086 \\
{[0.037]}\end{array}$ & & \\
\hline Mean of $\rho_{p r}$ if below median & & $\begin{array}{c}0.913 \\
{[0.032]}\end{array}$ & & \\
\hline Mean of $\rho_{p r}$ if above median & & $\begin{array}{c}1.047 \\
{[0.024]}\end{array}$ & & \\
\hline Real rent growth & & & $\begin{array}{c}0.014 \\
{[0.041]}\end{array}$ & \\
\hline S.d. of real rent growth & & & $\begin{array}{c}0.039 \\
{[0.017]}\end{array}$ & \\
\hline Mean residual time & & $\begin{array}{l}13.268 \\
{[1.862]}\end{array}$ & & \\
\hline Real median income & & & & $\begin{array}{l}2223.42 \\
{[245.80]}\end{array}$ \\
\hline Real median rent & & & & $\begin{array}{c}331.70 \\
{[39.212]}\end{array}$ \\
\hline Proportion of renters & & & & $\begin{array}{c}0.564 \\
{[0.125]}\end{array}$ \\
\hline Number of observations & 280 & 14 & 600 & 30 \\
\hline
\end{tabular}


Table 4: Partial effects from OLS regression of rental shares. Pooled cross-section for the period from 1984 to 2004. Table reports partial effects from ordinary least squares regression of equation (8). Partial effects are calculated at sample means of explanatory variables. Constant, profession dummies, and time dummies are not reported. Bootstrap standard errors are reported in parenthesis. Number of replications is $200 . \bar{R}^{2}$ is the adjusted $R^{2}{ }^{* * *}$ significant at $1 \%$-level ${ }^{* *}$ significant at $5 \%$-level ${ }^{*}$ significant at $10 \%$-level.

\begin{tabular}{lcccc}
\hline \hline \multicolumn{4}{c}{ Dependent variable: Profession-region } & rental share \\
\hline & \multicolumn{2}{c}{ Specification 1} & \multicolumn{2}{c}{ Specification 2} \\
\cline { 2 - 5 }$\rho_{p r}$ & $0.138^{* * *}$ & {$[0.026]$} & $0.093^{* * *}$ & {$[0.023]$} \\
$\bar{\mu}(\tau)_{p r, t}$ & $-0.027^{* * *}$ & {$[0.001]$} & $-0.016^{* * *}$ & {$[0.003]$} \\
Income & & & -0.001 & {$[0.000]$} \\
No assets & & & $0.055^{* *}$ & {$[0.025]$} \\
Price/Household income & & & $0.004^{* * *}$ & {$[0.001]$} \\
Age & & -0.001 & {$[0.001]$} \\
Education & & $0.011^{* * *}$ & {$[0.003]$} \\
Female & & 0.021 & {$[0.014]$} \\
Household size & & $-0.020^{* * *}$ & {$[0.008]$} \\
Children & & $-0.074^{* * *}$ & {$[0.021]$} \\
Married & & $-0.039^{*}$ & {$[0.026]$} \\
Foreigner & & $0.344^{* * *}$ & {$[0.018]$} \\
\hline Observations & 3935 & 3935 & \\
$\bar{R}^{2}$ & 0.250 & 0.356 & \\
\hline \hline
\end{tabular}


Table 5: Partial effects from probit model for recent movers. Pooled cross-section for the period from 1985 to 2004. Table reports partial effects from probit estimates of equation (9). Partial effects are calculated at sample means of explanatory variables. Constant, profession-dummies, and time-dummies are not reported. Bootstrap standard standard are reported in parenthesis. Number of replications is 200. The pseudo $R^{2}$ is computed as $1-\mathcal{L}_{u r} / \mathcal{L}_{o}$, where $\mathcal{L}_{u r}$ is the $\log$ likelihood value of the unrestricted model and $\mathcal{L}_{o}$ the $\log$ likelihood value of a constant only model. ${ }^{* * *}$ significant at $1 \%$-level ${ }^{* *}$ significant at $5 \%$-level * significant at $10 \%$-level.

\begin{tabular}{lcccc}
\hline \hline \multicolumn{4}{c}{ Binary dependent variable: Household is renter } \\
\hline & \multicolumn{3}{c}{ Specification 1} & \multicolumn{2}{c}{ Specification 2} \\
\cline { 2 - 5 }$\rho_{p r}$ & $0.131^{* *}$ & {$[0.056]$} & $0.117^{* *}$ & {$[0.053]$} \\
$\bar{\mu}(\tau)_{p r, t}$ & $-0.028^{* * *}$ & {$[0.001]$} & $-0.006^{* *}$ & {$[0.003]$} \\
Income & & & $-0.001^{* * *}$ & {$[0.000]$} \\
No assets & & $0.095^{* * *}$ & {$[0.014]$} \\
Price/Household income & & $0.006^{* * *}$ & {$[0.001]$} \\
Age & & $-0.003^{* * *}$ & {$[0.001]$} \\
Education & & $-0.004^{*}$ & {$[0.002]$} \\
Female & & 0.003 & {$[0.014]$} \\
Household size & & $-0.013^{*}$ & {$[0.008]$} \\
Kids & & $-0.052^{* *}$ & {$[0.020]$} \\
Married & & $-0.141^{* * *}$ & {$[0.019]$} \\
Foreigner & & $0.137^{* * *}$ & {$[0.010]$} \\
\hline Observations & 5820 & 5820 & \\
Log likelihood & -2635.34 & -2397.53 & \\
Pseudo $R^{2}$ & 0.136 & 0.214 & \\
\hline \hline
\end{tabular}




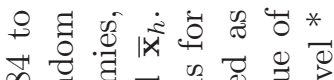
落 द्व च

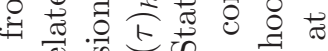

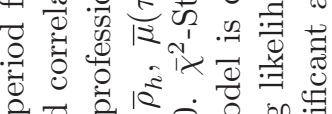
类

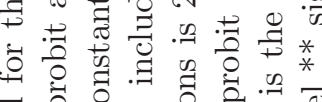

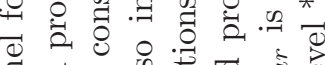

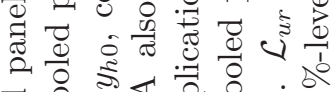

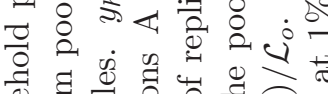

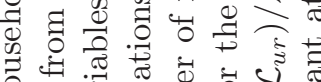

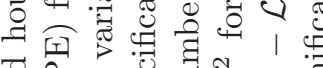

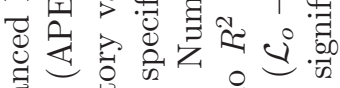

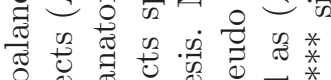

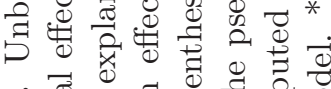

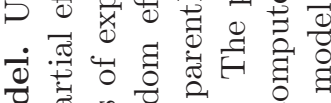

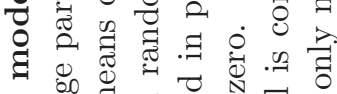

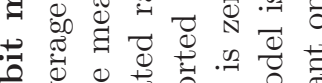

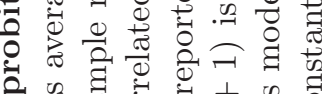
范

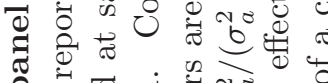
औ च ن क्षे ते . ส

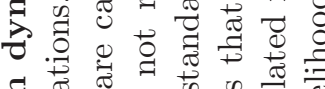
ह1:

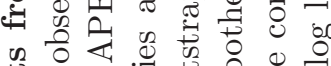

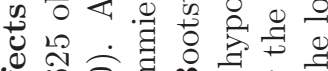

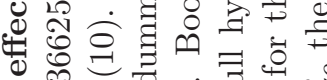

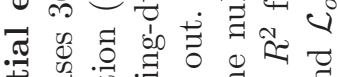

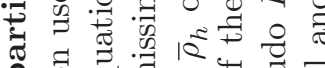
2.00 可

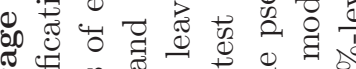
व

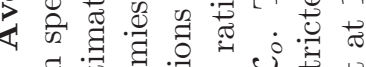
○

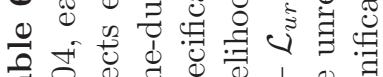

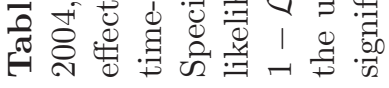

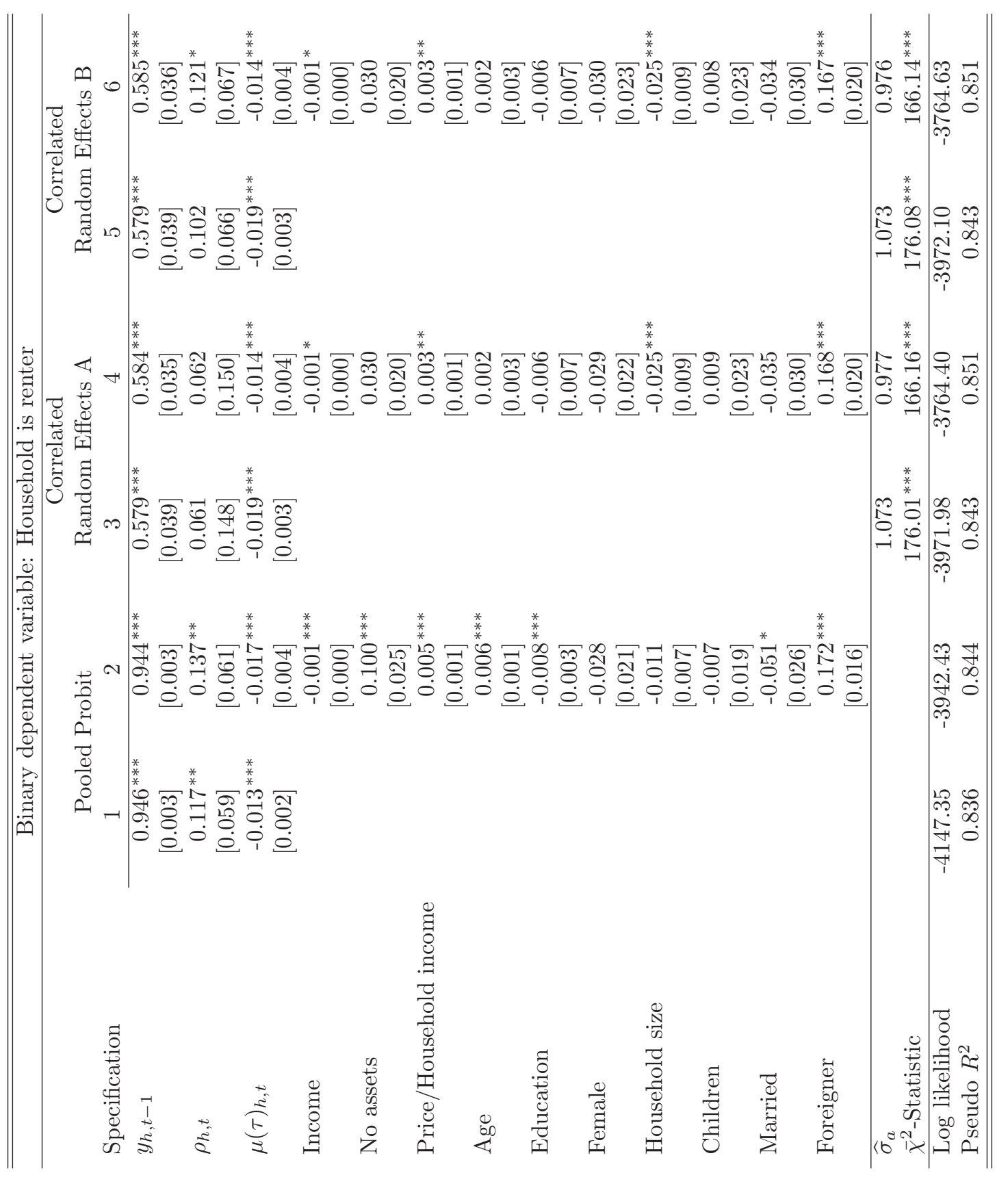




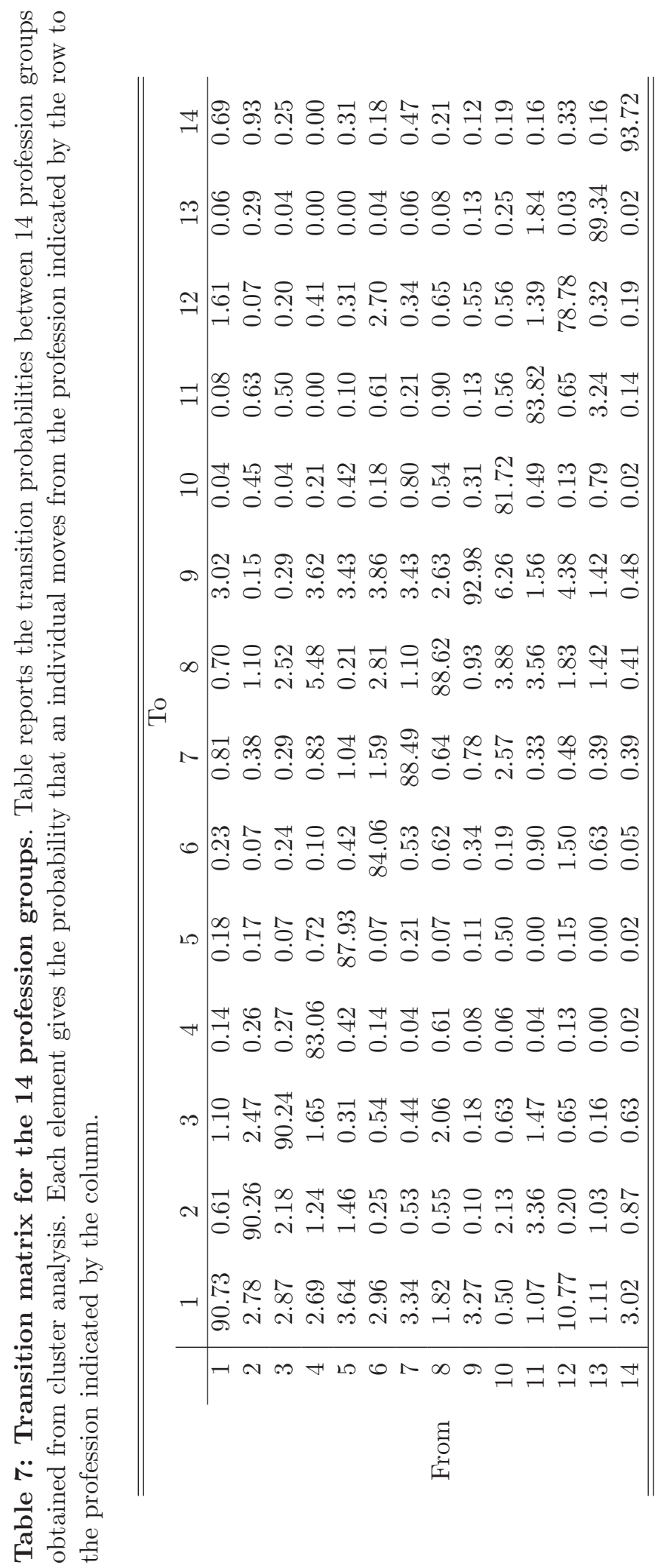


Table 8: Lognormal regression of residence spells. Table reports maximum likelihood estimates of equation (14). Constant and time dummies are not reported. Reported standard errors in parenthesis are robust to serial correlated errors. Akaike information criterion (AIC) is computed as $-2 \cdot \mathcal{L}+2 \cdot k$. $\mathcal{L}$ is the value of the $\log$ likelihood and $k=43$ the model degrees of freedom. Wald statistic is for the null hypothesis that reported coefficients on profession dummies are jointly zero. P-Value is for $\chi^{2}(14)$ distribution.

\begin{tabular}{lcr}
\hline \hline \multicolumn{3}{c}{ Dependent variable: Log residence duration } \\
\hline Age & $0.058^{* * *}$ & {$[0.009]$} \\
Age $^{2}$ & $-0.001^{* * *}$ & {$[0.000]$} \\
Dual-earner & $0.166^{* * *}$ & {$[0.034]$} \\
Household size $=2$ & $0.203^{* * *}$ & {$[0.037]$} \\
Household size $=3$ & $0.165^{* * *}$ & {$[0.047]$} \\
Household size $\geq 4$ & $0.374^{* * *}$ & {$[0.053]$} \\
Foreigner & $-0.090^{* * *}$ & {$[0.033]$} \\
Married & $0.374^{* * *}$ & {$[0.038]$} \\
Female & $-0.063^{* *}$ & {$[0.030]$} \\
Profession1 & $0.094^{* *}$ & {$[0.044]$} \\
Profession2 & 0.041 & {$[0.071]$} \\
Profession3 & 0.046 & {$[0.058]$} \\
Profession4 & -0.218 & {$[0.190]$} \\
Profession5 & -0.102 & {$[0.138]$} \\
Profession6 & $-0.300^{* * *}$ & {$[0.073]$} \\
Profession7 & 0.103 & {$[0.070]$} \\
Profession8 & 0.026 & {$[0.060]$} \\
Profession9 & 0.082 & {$[0.046]$} \\
Profession10 & -0.059 & {$[0.088]$} \\
Profession11 & 0.075 & {$[0.106]$} \\
Profession12 & 0.121 & {$[0.087]$} \\
Profession13 & 0.156 & {$[0.135]$} \\
Profession14 & 0.104 & {$[0.075]$} \\
\hline $\ln \sigma$ & $0.025^{* *}$ & {$[0.010]$} \\
\hline No of observations & 38343 & No of Spells \\
Log likelihood & -8513.23 & AIC \\
\hline Wald statistics & 42.241 & P-Value \\
\hline \hline
\end{tabular}




\section{SFB 649 Discussion Paper Series 2009}

For a complete list of Discussion Papers published by the SFB 649, please visit http://sfb649.wiwi.hu-berlin.de.

001 "Implied Market Price of Weather Risk" by Wolfgang Härdle and Brenda López Cabrera, January 2009.

002 "On the Systemic Nature of Weather Risk" by Guenther Filler, Martin Odening, Ostap Okhrin and Wei Xu, January 2009.

003 "Localized Realized Volatility Modelling" by Ying Chen, Wolfgang Karl Härdle and Uta Pigorsch, January 2009.

004 "New recipes for estimating default intensities" by Alexander Baranovski, Carsten von Lieres and André Wilch, January 2009.

005 "Panel Cointegration Testing in the Presence of a Time Trend" by Bernd Droge and Deniz Dilan Karaman Örsal, January 2009.

006 "Regulatory Risk under Optimal Incentive Regulation" by Roland Strausz, January 2009.

007 "Combination of multivariate volatility forecasts" by Alessandra Amendola and Giuseppe Storti, January 2009.

008 "Mortality modeling: Lee-Carter and the macroeconomy" by Katja Hanewald, January 2009.

009 "Stochastic Population Forecast for Germany and its Consequence for the German Pension System" by Wolfgang Härdle and Alena Mysickova, February 2009.

010 "A Microeconomic Explanation of the EPK Paradox" by Wolfgang Härdle, Volker Krätschmer and Rouslan Moro, February 2009.

011 "Defending Against Speculative Attacks" by Tijmen Daniëls, Henk Jager and Franc Klaassen, February 2009.

012 "On the Existence of the Moments of the Asymptotic Trace Statistic" by Deniz Dilan Karaman Örsal and Bernd Droge, February 2009.

013 "CDO Pricing with Copulae" by Barbara Choros, Wolfgang Härdle and Ostap Okhrin, March 2009.

014 "Properties of Hierarchical Archimedean Copulas" by Ostap Okhrin, Yarema Okhrin and Wolfgang Schmid, March 2009.

015 "Stochastic Mortality, Macroeconomic Risks, and Life Insurer Solvency" by Katja Hanewald, Thomas Post and Helmut Gründl, March 2009.

016 "Men, Women, and the Ballot Woman Suffrage in the United States" by Sebastian Braun and Michael Kvasnicka, March 2009.

017 "The Importance of Two-Sided Heterogeneity for the Cyclicality of Labour Market Dynamics" by Ronald Bachmann and Peggy David, March 2009.

018 "Transparency through Financial Claims with Fingerprints - A Free Market Mechanism for Preventing Mortgage Securitization Induced Financial Crises" by Helmut Gründl and Thomas Post, March 2009.

019 "A Joint Analysis of the KOSPI 200 Option and ODAX Option Markets Dynamics" by Ji Cao, Wolfgang Härdle and Julius Mungo, March 2009.

020 "Putting Up a Good Fight: The Galí-Monacelli Model versus 'The Six Major Puzzles in International Macroeconomics'", by Stefan Ried, April 2009.

021 "Spectral estimation of the fractional order of a Lévy process" by Denis Belomestny, April 2009.

022 "Individual Welfare Gains from Deferred Life-Annuities under Stochastic Lee-Carter Mortality" by Thomas Post, April 2009.

\section{SFB 649, Spandauer Straße 1, D-10178 Berlin http:/ / sfb649.wiwi.hu-berlin.de}




\section{SFB 649 Discussion Paper Series 2009}

For a complete list of Discussion Papers published by the SFB 649, please visit http://sfb649. wiwi.hu-berlin.de.

023 "Pricing Bermudan options using regression: optimal rates of convergence for lower estimates" by Denis Belomestny, April 2009.

024 "Incorporating the Dynamics of Leverage into Default Prediction" by Gunter Löffler and Alina Maurer, April 2009.

025 "Measuring the effects of geographical distance on stock market correlation" by Stefanie Eckel, Gunter Löffler, Alina Maurer and Volker Schmidt, April 2009.

026 "Regression methods for stochastic control problems and their convergence analysis" by Denis Belomestny, Anastasia Kolodko and John Schoenmakers, May 2009.

027 "Unionisation Structures, Productivity, and Firm Performance" by Sebastian Braun, May 2009.

028 "Optimal Smoothing for a Computationally and Statistically Efficient Single Index Estimator" by Yingcun Xia, Wolfgang Härdle and Oliver Linton, May 2009.

029 "Controllability and Persistence of Money Market Rates along the Yield Curve: Evidence from the Euro Area" by Ulrike Busch and Dieter Nautz, May 2009.

030 "Non-constant Hazard Function and Inflation Dynamics" by Fang Yao, May 2009.

031 "De copulis non est disputandum - Copulae: An Overview" by Wolfgang Härdle and Ostap Okhrin, May 2009.

032 "Weather-based estimation of wildfire risk" by Joanne Ho and Martin Odening, June 2009.

033 "TFP Growth in Old and New Europe" by Michael C. Burda and Battista Severgnini, June 2009.

034 "How does entry regulation influence entry into self-employment and occupational mobility?" by Susanne Prantl and Alexandra Spitz-Oener, June 2009.

035 "Trade-Off Between Consumption Growth and Inequality: Theory and Evidence for Germany" by Runli Xie, June 2009.

036 "Inflation and Growth: New Evidence From a Dynamic Panel Threshold Analysis" by Stephanie Kremer, Alexander Bick and Dieter Nautz, July 2009.

037 "The Impact of the European Monetary Union on Inflation Persistence in the Euro Area" by Barbara Meller and Dieter Nautz, July 2009.

038 "CDO and HAC" by Barbara Choroś, Wolfgang Härdle and Ostap Okhrin, July 2009.

039 "Regulation and Investment in Network Industries: Evidence from European Telecoms" by Michał Grajek and Lars-Hendrik Röller, July 2009.

040 "The Political Economy of Regulatory Risk" by Roland Strausz, August 2009.

041 "Shape invariant modelling pricing kernels and risk aversion" by Maria Grith, Wolfgang Härdle and Juhyun Park, August 2009.

042 "The Cost of Tractability and the Calvo Pricing Assumption" by Fang Yao, September 2009.

\section{SFB 649, Spandauer Straße 1, D-10178 Berlin http:/ / sfb649.wiwi.hu-berlin.de}

This research was supported by the Deutsche Forschungsgemeinschaft through the SFB 649 "Economic Risk".

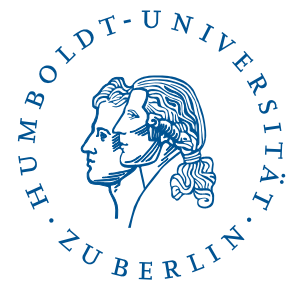




\section{SFB 649 Discussion Paper Series 2009}

For a complete list of Discussion Papers published by the SFB 649, please visit http://sfb649.wiwi.hu-berlin.de.

043 "Evidence on Unemployment, Market Work and Household Production" by Michael C. Burda and Daniel S. Hamermesh, September 2009.

044 "Modelling and Forecasting Liquidity Supply Using Semiparametric Factor Dynamics" by Wolfgang Karl Härdle, Nikolaus Hautsch and Andrija Mihoci, September 2009.

045 "Quantifizierbarkeit von Risiken auf Finanzmärkten" by Wolfgang Karl Härdle and Christian Wolfgang Friedrich Kirchner, October 2009.

046 "Pricing of Asian temperature risk" by Fred Benth, Wolfgang Karl Härdle and Brenda López Cabrera, October 2009.

047 "MM-Stat - MultiMedia-Statistik: Statistische Datenanalyse - webbasiert, interaktiv und multimedial" by Sigbert Klinke, Dina Kuhlee, Christian Theel, Cornelia Wagner and Christian Westermeier, October 2009.

048 "Migration of the Highly Skilled: Can Europe catch up with the US?" by Lydia Mechtenberg and Roland Strausz, October 2009.

049 "A blocking and regularization approach to high dimensional realized covariance estimation" by Nikolaus Hautsch, Lada M. Kyj and Roel C.A. Oomen, October 2009.

050 "Generalized single-index models: The EFM approach" by Xia Cui, Wolfgang Karl Härdle and Lixing Zhu, October 2009.

051 "The Market Impact of a Limit Order" by Nikolaus Hautsch and Ruihong Huang, October 2009.

052 "On economic evaluation of directional forecasts" by Oliver Blaskowitz and Helmut Herwartz, October 2009.

053 "Monetary Policy Implementation and Overnight Rate Persistence" by Dieter Nautz and Jan Scheithauer, November 2009.

054 "Depression Econometrics: A FAVAR Model of Monetary Policy During the Great Depression" by Pooyan Amir Ahmadi and Albrecht Ritschl, November 2009.

055 "Representations for optimal stopping under dynamic monetary utility functionals" by Volker Krätschmer and John Schoenmakers, November 2009.

056 "Product policy and the East-West productivity gap" by Bernd Görzig, Martin Gornig, Ramona Voshage and Axel Werwatz, November 2009.

057 "Real and Nominal Rigidities in Price Setting: A Bayesian Analysis Using Aggregate Data" by Fang Yao, November 2009.

058 "Polar sets of anisotropic Gaussian random fields" by Jakob Söhl, November 2009.

059 "Der Einfluss von Exporten auf die betriebliche Entwicklung" by Stefan Mangelsdorf, November 2009.

060 "Renting versus Owning and the Role of Income Risk: The Case of Germany" by Rainer Schulz, Martin Wersing and Axel Werwatz, December 2009. 